NOTICE: this is the author's version of a work that was accepted for publication in Mechanics of Materials. Changes resulting from the publishing process, such as peer review, editing, corrections, structural formatting, and other quality control mechanisms may not be reflected in this document. Changes may have been made to this work since it was submitted for publication. A definitive version was subsequently published in Mechanics of Materials, Volume 54, November 2012, Pages 113-123, http://dx.doi.org/10.1016/j.mechmat.2012.07.006, 


\title{
Characterization of stress-strain relationships of elastoplastic materials: An improved method with conical and pyramidal indenters
}

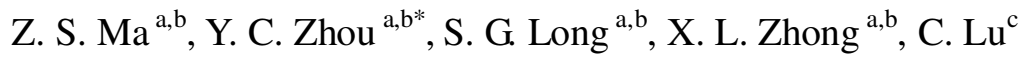 \\ ${ }^{a}$ Key Laboratory of Low Dimensional Materials \& Application Technology of \\ Ministry of Education, Xiangtan University, Hunan 411105, China \\ ${ }^{b}$ Faculty of Materials, Optoelectronics and Physics, Xiangtan University, Hunan \\ 411105, China \\ ${ }^{c}$ Department of Mechanical Engineering, Curtin University, Western Australia 6845 , \\ Australia
}

\begin{abstract}
The load-displacement curve in indentation is widely used to extract elastoplastic properties of materials. It is believed that such a measurement is non-unique and a full stress-strain curve cannot be obtained with a sharp indenter or even plural and spherical indenters. By introducing a ratio of the additional residual area to the area of a profile indenter, we proposed a new set of dimensionless functions. Based on these functions and finite element simulations, analytical expressions were derived between indentation data and elastoplastic properties. It is shown that this method can effectively distinguish highly elastic and plastic solids (Cheng and Cheng, 1999) and mystical materials (Chen et al., 2007), which provides a useful guideline for properly using the indentation technique to measure elastoplastic properties of materials with conical and pyramidal indenters.
\end{abstract}

Keywords: Indentation; Mechanical properties; Uniqueness; Finite element simulation

\footnotetext{
* Corresponding author: Tel.: +86 731 58293586; fax: +86 73158293586.

E-mail address: zhouyc@xtu.edu.cn (Y. Zhou)
} 


\section{Introduction}

Over nearly a century, indentation tests have been widely applied to obtain mechanical properties of materials (Tabor, 1996). Based on methods proposed by Doerner and Nix (1986), Oliver and Pharr (1992), Cheng and Cheng (1998), and Ma et al. (2012), hardness and elastic modulus of a material can be calculated from loading-unloading curves. According to the concept of self-similarity, the results obtained from an elastoplastic indentation response are very simple but not general. For example, Hill et al. (1989) developed a self-similar solution of a power-law plastic material under spherical indentation, where the rigorous theoretical basis is Meyer's law. Recently, self-similar approximations of sharp (e.g., Berkovich and Vickers) indentation were obtained for an elastoplastic material by Giannakopoulos et al. (1999) and Larsson et al. (1996). Scaling functions were also applied to study bulk (Cheng and Cheng, 1998a,b; Cheng and Cheng, 1999) and coated materials (Tunvisut et al., 2001; Huber et al., 2002). Here, Kick's law (i.e., $P=C h^{2}$ during loading, with $P$ the indentation load, $h$ the indentation depth, and the loading curvature $C$ being a material constant) is a natural outcome of the dimensional analysis on sharp indentation (Cheng and Cheng, 1998a). It is shown that, by matching loading and unloading curves obtained from finite element simulations with measurements, the stress-strain relationship of a material can be extracted (Myers et al., 1998; Dao et al., 2001; Ogasawara et al., 2005). For most metals and alloys, their stress-strain $(\sigma-\varepsilon)$ relationships can be expressed by a power-law as

$$
\sigma=E \varepsilon \text { for } \varepsilon \leq \sigma_{\mathrm{y}} / E \text { and } \sigma=R \varepsilon^{n} \text { for } \varepsilon \geq \sigma_{\mathrm{y}} / E
$$


where $E$ is the elastic modulus, $n$ is the work-hardening exponent, $\sigma_{\mathrm{y}}$ is the yield strength, and $R \equiv \sigma_{\mathrm{y}}\left(E / \sigma_{\mathrm{y}}\right)^{n}$ is the work-hardening rate. For metals and alloys, the value of Poisson's ratio $v$ is in the range of 0.25 to 0.35 and here, $v=0.3$ is chosen.

To fully characterize the elastoplastic properties of a power-law stress-free material, three independent parameters $\left(E, \sigma_{\mathrm{y}}, n\right)$ are needed. In recent years, how to obtain these parameters has been a research focus (Huber and Tsakmakis, 1999a,b; Cheng and Cheng, 2004; Swaddiwudhipong et al., 2005; Chen et al., 2007; Luo and Lin, 2007). For instance, the indentation load-displacement relationship of an elastic-plastic material was supposed to be a linear combination of elastic and elastic-perfectly plastic response (Swaddiwudhipong et al., 2005; Luo and Lin, 2007), and then an optimization method was introduced in reverse analysis. Further, several fundamental problems in the reverse analysis were studied such as the sensitivity (Bucaille et al., 2003; Chollacoop et al., 2003; Cao and Lu, 2004; Zhao et al., 2006; Lan and Venkatesh, 2007) and uniqueness of reverse solutions (Cheng and Cheng, 1999; Capehart and Cheng, 2003; Alkorta et al., 2005; Chen et al., 2007). In indentation techniques, however, the existence of a solution requires that the indentation response be unique for a given material. That is, there is a one-to-one correspondence between the shape factors of load-displacement curves and elastoplastic properties. In the work of Dao et al. (2001), a computational study was undertaken to identify the extent to which the elastoplastic properties of ductile materials could be determined by instrumented sharp indentation and to quantify their sensitivity to variations of indentation data. They concluded that the unique properties 
can be obtained by a sharp indentation curve. However, when the apex angle of a sharp indenter is fixed, it is shown that a set of materials with distinct elastoplastic properties may yield almost the same indentation curve (Cheng and Cheng, 1999; Capehart and Cheng, 2003; Tho et al., 2004; Alkorta et al., 2005). It implies that the mechanical properties of these materials cannot be uniquely determined by using one sharp indenter. Therefore, it is believed that the dual (or plural) sharp indentation analyses would obtain a unique solution because, when another sharp indenter is used, it is unlikely that they exhibit the same indentation characteristics (Futakawa et al., 2001; Bucaille et al., 2003; Capehart and Cheng, 2003; Chollacoop et al., 2003; DiCarlo et al., 2003; Cao and Lu, 2004; Cheng and Cheng, 2004; Tho et al., 2004; Alkorta et al., 2005; Cao and Huber, 2006; Luo and Lin, 2007; Le, 2008; Le, 2009).

Recently, the unique solution in reverse analysis with dual indenters was investigated by Chen et al. (2007). They demonstrated the existence of mystical materials that experience almost identical $P-h$ curves for different indenters with half included angles ranging from $60^{\circ}$ to $80^{\circ}$. They have also indicated that two mystical materials associated to dual indenters must exhibit a fair difference in elastic modulus, which is within $10 \%$ for all pairs of mystical materials (Chen et al., 2007) and rapidly reduces when increasing the difference between the apex angles of dual indenters. For specific dual indenters with $\theta_{1}=70.3^{\circ}, \theta_{2}=80^{\circ}$ and $\theta_{1}=70.3^{\circ}, \theta_{2}=63.14^{\circ}$, only low strain hardening materials $(n \leq 0.2)$ with $\sigma_{\mathrm{y}} / E \approx 0.01$ might be mystical. For the common dual indenters $\left(\theta_{1}=70.3^{\circ}\right.$ and $\left.\theta_{2}=60^{\circ}\right)$, there are few useful mystical materials. Hence, the material properties (e.g., $E, \sigma_{\mathrm{y}}, n$ ) cannot be uniquely 
determined by a $P-h$ curve with a sharp indenter (Cheng and Cheng, 1999; Chen et al., 2007) and even a sphere indenter (Lee et al., 2005; Liu et al., 2009). Until now, to the best of our knowledge, there is no effective method to extract the unique material properties from one indentation response. Therefore, it is necessary to find out a new parameter that is independent of the indentation $P-h$ curve. According to recent studies, the geometrical shape relevant to indentation imprint is considered as an important experimental information, which is supplementary to the usual one such as indentation depths at various maximum loads (Bolzon et al., 2004; Bocciarelli et al., 2005; Bocciarelli and Bolzon, 2007; Lu et al., 2007; Bocciarelli et al., 2008; Bolzon et al., 2010). Thus, the elastic-plastic material parameters could be uniquely determined with an innovative provision of measuring the imprint geometry besides load-displacement curves in indentation tests.

In this paper, by introducing an additional dimensionless function of pile-up area, we present a new method for extracting the elastoplastic properties of materials from sharp indentation. The uniqueness of a reverse problem is analyzed in Section 2 and an improved indentation model is established in Section 3. Based on the conical indenter $\left(\theta=70.3^{\circ}\right)$, Section 4 discusses two groups of special materials (Cheng and Cheng, 1999) and a group of mystical materials (Chen et al., 2007). With a true triangular pyramid indenter, a finite element model is built up and its effectiveness is evaluated by indentation tests in Section 5. Finally, a brief summary is given in Section 6 . 


\section{Uniqueness of indentation curves}

In the $P-h$ curve obtained from a bulk material, there are three commonly used independent shape parameters: the loading curvature $C=P / h^{2}$, the contact stiffness $S=\mathrm{d} P /\left.\mathrm{d} h\right|_{h=h_{\mathrm{m}}} ^{\text {unloaing }}$, and the ratio between the residual penetration and maximum indentation depths $h_{\mathrm{r}} / h_{\mathrm{m}}$ (Giannakopoulos and Suresh, 1999; Dao et al., 2001; Zeng and Chiu, 2001; Casals and Alcalá, 2005). Based on the dimensional analysis of a given indenter, the following dimensionless quantities are suggested to characterize the shape of a $P-h$ curve (Cheng and Cheng, 1999; Cheng and Cheng, 2004; Alkorta et al., 2005), that is

$$
\begin{gathered}
\frac{P}{E h^{2}}=\frac{P_{\mathrm{m}}}{E h_{\mathrm{m}}^{2}}=\Pi_{1}\left(\frac{\sigma_{\mathrm{y}}}{E}, n\right)=\frac{C}{E} \\
\frac{S}{E h^{2}}=\Pi_{2}\left(\frac{\sigma_{\mathrm{y}}}{E}, n\right)=\frac{b C}{E}\left(1-\frac{h_{\mathrm{r}}}{h}\right)^{-1} \\
\frac{h_{\mathrm{r}}}{h}=\Pi_{3}\left(\frac{\sigma_{\mathrm{y}}}{E}, n\right) \\
\frac{W_{\mathrm{p}}}{W_{\mathrm{t}}}=\Pi_{4}\left(\frac{\sigma_{\mathrm{y}}}{E}, n\right)=1-\frac{3}{1+b}\left(1-\frac{h_{\mathrm{r}}}{h}\right)
\end{gathered}
$$

where $W_{\mathrm{p}}$ and $W_{\mathrm{t}}$ are the plastic work and the total work, respectively, $b$ is the exponent of a power-law fitting to the unloading curve, and $P=C^{\prime}\left(h-h_{\mathrm{r}}\right)^{b}$ with $C^{\prime}=C h_{\mathrm{m}}^{2} /\left(h_{\mathrm{m}}-h_{\mathrm{r}}\right)^{b}$ (Alkorta et al., 2005). For two different materials, the $P-h$ curves may be indistinguishable if their shape factors in Eqs. $\left(2 a^{-}-2 d\right)$ are sufficiently close. According to finite element simulations on a large range of materials, Alkorta et al. (2005) and Tho et al. (2004) found out that the exponent $b$ of an unloading curve is dependent on $W_{\mathrm{p}} / W_{\mathrm{t}}$. Therefore, only two are independent of the four shape factors 
in Eq. (2). That is, it seems impossible to extract the mechanical properties $\left(E, \sigma_{\mathrm{y}}, n\right)$ by using a sharp indentation. Numerical studies have also shown that the $P-h$ curves for a special group of materials (with different values of $E, \sigma_{\mathrm{y}}$, and $n$ ) are visually indistinguishable (Alkorta et al., 2005). To obtain additional information, therefore, a dual (or plural) indenter is used in indentation. Due to the lack of unique solutions, however, it is shown that, by available techniques, several mystical materials are unable to be distinguishable (Chen et al., 2007; Liu et al., 2009). Thus, there is still not a method that can uniquely extract the mechanical properties $\left(E, \sigma_{\mathrm{y}}, n\right)$ from one indentation $P-h$ curve measured with a sharp indenter because there are only two independent parameters.

\section{A new theoretical framework}

\subsection{Pile-up effect}

Let us consider whether an indentation profile that is sensitive to plastic deformation can be introduced as another independent variable (Bolshakov and Pharr, 1998; Tunvisut et al., 2001; Matsuda, 2002; Tunvisut et al., 2002; Mata and Alcalá, 2003; Smith et al., 2003; Taljat and Pharr, 2004; Wang et al., 2004; Gao, 2006; Lee et al., 2007). For elastic-plastic materials, the indentation pile-up or sink-in depends on their strain-hardening characteristics (Norbury and Samuel, 1928; Tabor, 1951; Barnett and Tetelman, 1966; Matthews, 1980; Hill et al., 1989; Biwa and Storakers, 1995; Field and Swain, 1995; Bellemare et al., 2007). Matthews (1980) suggested an empirical relationship between the contact depth $h_{\mathrm{c}}$ and the maximum depth $h$, which 
can be represented as

$$
\frac{h_{\mathrm{c}}}{h}=\frac{1}{2}\left(\frac{2+n}{2}\right)^{2(1-n) / n}
$$

Based on the plastic deformation theory (Hill et al., 1989), the relationship between $n$ and $h_{\mathrm{c}} / h$ for a power-law hardening material can be approximated as

$$
\frac{h_{\mathrm{c}}}{h}=\frac{5}{2}\left(\frac{2-n}{4+n}\right)
$$

Fig. 1 shows a comparison of theoretical analyses (Hill et al., 1989; Biwa and Storakers, 1995) and experimental data for a variety of metals (Norbury and Samuel, 1928). It is seen that the degree of pile-up or sink-in, as defined by a normalized parameter $h_{\mathrm{c}} / h$, depends on the strain hardening exponent $n$ and the ratio $\sigma_{\mathrm{y}} / E$. The smaller the strain hardening exponent $n$ and the ratio $\sigma_{y} / E$, the easier the pile-up appears. Thus, an indentation residual profile is sensitive to plastic deformation. The uniqueness of reverse analysis could be solved by introducing a new parameter relative to the indentation residual profile, which can be determined by atomic force microscope or scanning probe microscope. It is worth noting that, however, more complicated experimental techniques are required to exactly measure indentation residual profiles at nano-scales.

\subsection{A dimensionless function $\Delta A / A$}

Due to the difficulty in measuring $h_{\mathrm{c}}$ in indentation during loading, an additional residual area is introduced, which is related to the plastic deformation $\Delta A$ after unloading, as illustrated in Fig. 2. In the case of pile-up, $\Delta A$ is positive, and in 
sink-in, it is negative. Here, $A$ is the area of an indentation profile (relative to the original surface) at $h_{m}$. Then, a new dimensionless function $\Delta A$ / $A$, independent of the indentation $P-h$ curve, can be defined. Combining it with two independent dimensionless functions in Eq. (2), we can obtain

$$
\begin{gathered}
\frac{P}{E h^{2}}=\frac{P_{\mathrm{m}}}{E h_{\mathrm{m}}^{2}}=\Psi_{1}\left(\frac{\sigma_{\mathrm{y}}}{E}, n\right) \\
\frac{W_{\mathrm{p}}}{W_{\mathrm{t}}}=\Psi_{2}\left(\frac{\sigma_{\mathrm{y}}}{E}, n\right) \\
\frac{\Delta A}{A}=\Psi_{3}\left(\frac{\sigma_{\mathrm{y}}}{E}, n\right)
\end{gathered}
$$

Solving Eq. (5) by using the software MATLAB 6.5, the mechanical properties $\left(E, \sigma_{\mathrm{y}}, n\right)$ can be extracted from one sharp indentation.

\section{Case study with a conical indenter}

\subsection{Finite element model}

In a two-dimensional model for an axisymmetric conical indenter $\left(\theta=70.3^{\circ}\right)$, a total of 9,100 four-node bilinear axisymmetric elements are used to model semi-infinite substrate with the ABAQUS STANDARD (ABAQUS, 2005) finite element solver, as shown in Fig. 3. The indenter is approximated as a perfectly rigid sharp tip. In finite element simulations, the von Mises yield criterion is chosen and large deformation formulations are included. As shown in Fig. 3(a), the specimen is fixed in the vertical direction but it can freely slide or deform in the horizontal direction. In order to simulate elastic-plastic properties of metals, the elastic modulus $E$ ranges from 30 to $300 \mathrm{GPa}$, the yield strength $\sigma_{\mathrm{y}}$ is from 30 to $3000 \mathrm{MPa}$, and the 
strain hardening exponent $n$ is from 0 to 0.5 .

\subsection{Dimensionless functions}

In Fig. 4(a), $\Psi_{1}$ increases with the increase of the hardening exponent $n$ and the ratio $\sigma_{\mathrm{y}} / E$. Oppositely, $\Psi_{2}$ decreases with the increase of $n$ and $\sigma_{\mathrm{y}} / E$, see Fig. 4(b). $\Psi_{3}$ can be more or less than zero, corresponding to pile-up or sink-in profiles after unloading, as shown in Fig. 4(c). By fitting the simulation results in Fig. 4 and minimizing the error within $\pm 2.01 \%$, we have

$$
\begin{gathered}
\frac{P_{\mathrm{m}}}{E h_{\mathrm{m}}^{2}}=\Psi_{1}\left(\frac{\sigma_{\mathrm{y}}}{E}, n\right)=\frac{-0.01569+0.6358 n+104.64\left(\frac{\sigma_{\mathrm{y}}}{E}\right)}{1-0.494 n+45.33\left(\frac{\sigma_{\mathrm{y}}}{E}\right)} \\
\frac{W_{\mathrm{p}}}{W_{\mathrm{t}}}=\Psi_{2}\left(\frac{\sigma_{\mathrm{y}}}{E}, n\right)=1.4070-0.5 n^{1.5}+\frac{2.614}{\ln \left(\frac{\sigma_{\mathrm{y}}}{E}\right)} \\
\frac{\Delta A}{A}=\Psi_{3}\left(\frac{\sigma_{\mathrm{y}}}{E}, n\right)=\frac{0.2509-0.4727 n-6.9912\left(\frac{\sigma_{\mathrm{y}}}{E}\right)}{1+0.9807 n+114.555\left(\frac{\sigma_{\mathrm{y}}}{E}\right)-4039.79\left(\frac{\sigma_{\mathrm{y}}}{E}\right)^{2}}
\end{gathered}
$$

Then, solving these three dimensionless functions, the elastoplastic properties of an indented material can be inversely determined.

\subsection{Materials from Cheng and Cheng (1999)}

According to Cheng and Cheng (1999), there are two groups of materials that exhibit the same load-displacement curve. The first group of materials is highly plastic solids with the elastoplastic properties $\left(E, \sigma_{\mathrm{y}}, n\right)$ of (200 GPa, 2.36 GPa, 0), (200 GPa, 2.00 GPa, 0.1), and (200 GPa, 1.24 GPa, 0.3), respectively, see solid lines 
in Fig. 5(a). It is obvious that their loading and unloading curves in indentation are indistinguishable, as shown in Fig. 5(b). Therefore, with just a sharp indenter, the elastoplastic properties cannot be uniquely determined by Eq. (2). Fig. 5(c) illustrates a significant difference of their pile-up effects after unloading, where $\Delta A$ is equal to 0.033, 0.0253 and $0.014 \mu \mathrm{m}^{2}$, respectively, as listed in Table 1 . With the improved method or Eq. (6), their elastoplastic properties $\left(E, \sigma_{\mathrm{y}}, n\right)$ are determined as $(198.73$ GPa, 2.26 GPa, 0.0056), (197.75 GPa, 1.99 GPa, 0.099), and (226.48 GPa, 1.26 GPa, 0.295), which are consistent with input data (see Table 1), as shown in Fig. 5(a).

The other group of materials is highly elastic solids with the elastoplastic properties $\left(E, \sigma_{\mathrm{y}}, n\right)$ of (200 GPa, $\left.19 \mathrm{GPa}, 0\right),(200 \mathrm{GPa}, 15 \mathrm{GPa}, 0.3)$, and (200 GPa, 12 GPa, 0.5), respectively (Cheng and Cheng, 1999), see solid lines in Fig. 6(a). Although the mechanical properties of these three materials are remarkably different, their indentation behaviors are indistinguishable from loading and unloading curves, see Fig. 6(b). Similarly, with the improved method, their elastoplastic properties $\left(E, \sigma_{\mathrm{y}}\right.$, n) are determined as (203.47 GPa, 18.65 GPa, 0.000), (199.87 GPa, 15.19 GPa, 0.295), and (200.00 GPa, 13.17 GPa, 0.414), which are also consistent with input data. All deviations are less than $4 \%$ except for the modulus $E$ of the third highly plastic solid and the $n$ value of the third highly elastic solid, as shown in Fig. 7.

\subsection{Mystical materials from Chen et al. (2007)}

Chen et al. (2007) exhibited several pairs of mystical materials, as listed in Table

2. The first pair of mystical materials appears when using two different indenter 
angles $\left(70.3^{\circ}\right.$ and $\left.65^{\circ}\right)$. Their elastoplastic properties are, respectively, $E_{1}=100.00$ $\mathrm{GPa}, \sigma_{\mathrm{y} 1}=793.15 \mathrm{MPa}, n_{1}=0.02$ and $E_{2}=103.75 \mathrm{GPa}, \sigma_{\mathrm{y} 2}=600.68 \mathrm{MPa}, n_{2}=$ 0.15046. The loading and unloading curves have a good match for each other with the deviation less than $0.5 \%$ for all shape factors, as shown in Fig. 8(a). The values of $P_{\mathrm{m}}$, $W_{\mathrm{p}}$ and $W_{\mathrm{t}}$ are the same for two materials. However, there is a significant difference of $\Delta A$ with the values of 0.00648 and $0.0048 \mu \mathrm{m}^{2}$. Then, the elastoplastic properties of these mystical materials can be obtained by using Eq. (6), as shown in Fig. 8(b). The identified uniaxial stress-strain curves from reverse analysis are well agreement with their input data.

The second pair is called as extreme mystical materials with the elastoplastic properties of $E_{1}=100.00 \mathrm{GPa}, \sigma_{\mathrm{y} 1}=872.47 \mathrm{MPa}, n_{1}=0.0$ and $E_{2}=103.75 \mathrm{GPa}, \sigma_{\mathrm{y} 2}=$ 715.61 MPa, $n_{2}=0.10663$, respectively. They lead to almost the same indentation loading-unloading behaviors when the indenter angle changes from $60^{\circ}$ to $80^{\circ}$ (Chen et al., 2007), as shown in Fig. 9(a). That is, the existing dual (or plural) indentation methods fail to distinguish them. However, based on the difference of $\Delta A$ as shown in Fig. 9(a), we can obtain the elastoplastic properties of these mystical materials by using Eq. (6), as shown in Fig. 9(b). It is obvious that input data are agreement with the reverse analysis results, as listed in Table 2, and thus the method can effectively measure the plastic properties of ductile metals and alloys. All errors $\left(n_{1}\right.$ in the second pair of mystical materials cannot be counted since their true values are 0.0) are less than $3 \%$ except for $n_{1}$ that is about $50 \%$ for the first pair of mystical materials, as shown in Fig. 10. 


\section{Case study with a Berkovich indenter}

It is worth noting that, in the case of different indenters and friction between indenter and material, the dimensionless functions in Eq. (5) are various (Bolshakov and Pharr, 1998; McElhaney et al., 1998; Taljat and Pharr, 2004). Therefore, a new form of functions in Eq. (5) is required for a three-dimensional model of a Berkovich indenter.

\subsection{Finite element model}

There are three symmetry planes for a Berkovich indenter. Therefore, only one-sixth of the indenter is studied in a three-dimensional indentation model, as illustrated in Fig. 11. A typical mesh comprises about 28,000 8-node elements with the reduced integration. The rigid contact surface is supposed and the finite deformation is applied. The Coulomb's friction law is used between contact surfaces and the friction coefficient is 0.15 , which has a minor influence in indentation (Cheng and Cheng, 2004; Chen et al., 2007). The strain gradient effect is ignored because the indentation depth is sufficiently deep the same as the continuum mechanics applies to a bulk specimen. To simulate the elastic-plastic properties of metals, the elastic modulus $E$ is chosen from 30 to $300 \mathrm{GPa}$, the yield strength $\sigma_{\mathrm{y}}$ is from 30 to 3000 $\mathrm{MPa}$, and the strain hardening exponent $n$ is from 0 to 0.5 . As shown in Fig. 12, simulations are agreement with experiments by using a Berkovich indenter (Dao et al., 2001), where $E=66.8 \mathrm{GPa}, \sigma_{\mathrm{y}}=284 \mathrm{MPa}$ and $n=0.08$ for Al6061. 


\subsection{Dimensionless functions}

As shown in Fig. 13(a), $\Psi_{1}$ increases with the increase of the hardening exponent $n$ and the ratio $\sigma_{\mathrm{y}} / E$. Oppositely, $\Psi_{2}$ decreases with the increase of $n$ and $\sigma_{\mathrm{y}} / E$, see Fig. 13(b). In Fig. 13(c), $\Psi_{3}$ can be more or less than zero, which corresponds to pile-up or sink-in profiles after unloading. By fitting the simulation in

Fig. 13 and minimizing the error within $\pm 2.56 \%$, we have

$$
\begin{aligned}
& \left.\frac{P_{\mathrm{m}}}{E h_{\mathrm{m}}^{2}}=\Psi_{1}\left(\frac{\sigma_{\mathrm{y}}}{E}, n\right)=\frac{-0.02428+0.70 n+105.63\left(\frac{\sigma_{\mathrm{y}}}{E}\right)}{1-0.5441 n+39.75\left(\frac{\sigma_{\mathrm{y}}}{E}\right)}\right) \\
& \frac{W_{\mathrm{p}}}{W_{\mathrm{t}}}=\Psi_{2}\left(\frac{\sigma_{\mathrm{y}}}{E}, n\right)=1.0791-0.4332 n^{3 / 2}-2.5004\left(\frac{\sigma_{\mathrm{y}}}{E}\right)^{1 / 2} \\
& \frac{\Delta A}{A}=\Psi_{3}\left(\frac{\sigma_{\mathrm{y}}}{E}, n\right)=\frac{0.5171-0.8525 n-4.71\left(\frac{\sigma_{\mathrm{y}}}{E}\right)}{1+0.3128 n+89.229\left(\frac{\sigma_{\mathrm{y}}}{E}\right)+625.28\left(\frac{\sigma_{\mathrm{y}}}{E}\right)^{2}}
\end{aligned}
$$

To verify the effectiveness of these three dimensionless functions, the reverse analysis is carried out on indentation experiments for single crystal aluminum. The nanoindentation tests are conducted by using a TriboIndenter with a three-sided pyramidal Berkovich diamond indenter. The load and displacement resolutions are $100 \mathrm{nN}$ and $0.1 \mathrm{~nm}$, respectively. The single crystal aluminum is tested under the maximum load $P_{\max }=8000 \mu \mathrm{N}$ with the loading time of $20 \mathrm{~s}$ and the unloading time of $10 \mathrm{~s}$. To reduce noise of the creep curves, 8 measurements are repeated and their average value is taken. Before testing, the shape function of an indenter tip and the machine compliance are calibrated using a standard sample of fused quartz. The $P-h$ response and indentation profile after unloading are shown in Fig. 14(a). Based on Eq. 
(7), the mechanical properties of single crystal aluminum are calculated as, $E=82.39$ $\pm 1.38 \mathrm{GPa}, \sigma_{\mathrm{y}}=108.77 \pm 2.01 \mathrm{MPa}$, and $n=0.00$, which are well agreement with that measured by uniaxial tensile experiments, as shown in Fig. 14 (b). In this case, the deviations of $E$ and $\sigma_{\mathrm{y}}$ obtained from the reverse analysis are $9.86 \%$ and $2.61 \%$ in comparison with the uniaxial tension results. Here, it is worth noting that, in terms of pile-up or sink-in surface shapes due to local plastic deformation, whether the indentation solution is uniqueness is still an unsolved problem.

\section{Conclusions}

In this paper, by introducing another dimensionless function of $\triangle A / A$ in the reverse analysis, we have established the relationships between the indentation response and mechanical properties of materials. Based on a case study of indentation by an indenter with the half-apex angle $\theta=70.3^{\circ}$, it is shown that the improved method is efficient and accurate in characterizing the elastoplastic properties of materials. For highly plastic and elastic solids from Cheng and Cheng (1999) or mystical materials from Chen et al. (2007), we can successfully extract or distinguish the elastoplastic properties of these materials. In engineering applications, an improved model for a three-dimensional Berkovich indenter has been built up by numerical simulations. The results obtained by the reverse analysis are well agreement with tensile experiments. 


\section{Acknowledgments}

This work was supported by the National Natural Science Foundation of China (Nos. 11102176, 11172258, 11072208, 51172192 and 10828205), the Natural Science

Foundation of Hunan Province for Innovation Group (No. 09JJ7004), and the Key Special Program for Science and Technology of Hunan Province (No. 2009FJ1002). 


\section{References}

ABAQUS, 2005. ABAQUS 6.5 User's Manual. ABAQUS Inc.

Alkorta, J., Martinez-Esnaola, J.M., Sevillano, J.G., 2005. Absence of one-to-one correspondence between elastoplastic properties and sharp-indentation load-penetration data. J. Mater. Res. 20, 432-437.

Barnett, D.M., Tetelman, A.S., 1966. The stress distribution produced by screw dislocation pile-ups at rigid circular cylindrical inclusions. J. Mech. Phys. Solids 14, 329-348.

Bellemare, S., Dao, M., Suresh, S., 2007. The frictional sliding response of elasto-plastic materials in contact with a conical indenter. Int. J. Solids Struct. 44, 1970-1989.

Biwa, S., Storakers, B., 1995. An analysis of fully plastic Brinell indentation. J. Mech. Phys. Solids 43, 1303-1333.

Bocciarelli, M., Bolzon, G., 2007. Indentation and imprint mapping for the identification of constitutive parameters of thin layers on substrate: perfectly bonded interfaces. Mater. Sci. Eng. A 448, 303-314.

Bocciarelli, M., Bolzon, G., Maier, G., 2005. Parameter identification in anisotropic elastoplasticity by indentation and imprint mapping. Mech. Mater. 37, 855-868.

Bocciarelli, M., Bolzon, G., Maier, G., 2008. A constitutive model of metal-ceramic functionally graded material behavior: formulation and parameter identification. Comput. Mater. Sci. 43, 16-26.

Bolshakov, A., Pharr, G.M., 1998. Influences of pileup on the measurement of mechanical properties by load and depth sensing indentation techniques. J. Mater. Res. 13, 1049-1058.

Bolzon, G., Maier, G., Panico, M, 2004. Material model calibration by indentation, imprint mapping and inverse analysis. Int. J. Solids Struct. 41, 2957-2975.

Bolzon, G., Chiarullo, E.J., Egizabal, P., Estounes, C., 2010. Constitutive modelling and mechanical characterization of aluminium-based metal matrix composites produced by spark plasma sintering. Mech. Mater. 42, 548-558.

Bucaille, J.L., Stauss, S., Felder, E., Michler, J., 2003. Determination of plastic 
properties of metals by instrumented indentation using different sharp indenters. Acta Mater. 51, 1663-1678.

Cao, Y., Huber, N., 2006. Further investigation on the definition of the representative strain in conical indentation. J. Mater. Res. 21, 1810-1821.

Cao, Y.P., Lu, J., 2004. Depth-sensing instrumented indentation with dual sharp indenters: stability analysis and corresponding regularization schemes. Acta Mater. $52,1143-1153$.

Capehart, W., Cheng, Y.-T., 2003. Determining constitutive models from conical indentation: a sensitivity analysis. J. Mater. Res. 18, 827-832.

Casals, O., Alcalá, J., 2005. The duality in mechanical property extractions from Vickers and Berkovich instrumented indentation experiments. Acta Mater. 53, 3545-3561.

Chen, X., Ogasawara, N., Zhao, M., Chiba, N., 2007. On the uniqueness of measuring elastoplastic properties from indentation: the indistinguishable mystical materials. J. Mech. Phys. Solids 55, 1618-1660.

Cheng, Y.-T., Cheng, C.-M., 1998a. Scaling approach to conical indentation in elastic-plastic solids with work hardening. J. Appl. Phys. 84, 1284-1291.

Cheng, Y.-T., Cheng, C.-M., 1998b. Relationships between hardness, elastic modulus, and the work of indentation. Appl. Phys. Lett. 73, 614-616.

Cheng, Y.-T., Cheng, C.-M., 1999. Can stress-strain relationships be obtained from indentation curves using conical and pyramidal indenters? J. Mater. Res. 14, 3493-3496

Cheng, Y.-T., Cheng, C.-M., 2004. Scaling, dimensional analysis, and indentation measurements. Mater. Sci. Eng. R 44, 91-149.

Chollacoop, N., Dao, M., Suresh, S., 2003. Depth-sensing instrumented indentation with dual sharp indenters. Acta Mater. 51, 3713-3729.

Dao, M., Chollacoop, N., Van Vliet, K.J., Venkatesh, T.A., Suresh, S., 2001. Computational modeling of the forward and reverse problems in instrumented sharp indentation. Acta Mater. 49, 3899-3918.

DiCarlo, A., Yang, H.T.Y., Chandrasekar, S., 2003. Semi-inverse method for 
predicting stress-strain relationship from cone indentations. J. Mater. Res. 18, 2068-2078.

Doerner, M.F., Nix, W.D., 1986. A method for interpreting the data from depth-sensing indentation instruments. J. Mater. Res. 1, 601-609.

Field, J.S., Swain, M.V., 1995. Determining the mechanical properties of small volumes of material from submicrometer spherical indentations. J. Mater. Res. 10, $101-112$.

Futakawa, M., Wakui, T., Tanabe, Y., Ioka, I., 2001. Identification of the constitutive equation by the indentation technique using plural indenters with different apex angles. J. Mater. Res. 16, 2283-2292.

Gao, X.-L., 2006. An expanding cavity model incorporating strain-hardening and indentation size effects. Int. J. Solids Struct. 43, 6615-6629.

Giannakopoulos, A.E., Suresh, S., 1999. Determination of elastoplastic properties by instrumented sharp indentation. Scripta Mater. 40, 1191-1198.

Hill, R., Storakers, B., Zdunek, A.B., 1989. A theoretical study of the Brinell hardness test. Proc. Roy. Soc. London A 423, 301-330.

Huber, N., Tsakmakis, C., 1999a. Determination of constitutive properties fromspherical indentation data using neural networks. Part I: the case of pure kinematic hardening in plasticity laws. J. Mech. Phys. Solids 47, 1569-1588.

Huber, N., Tsakmakis, C., 1999b. Determination of constitutive properties fromspherical indentation data using neural networks. Part II: plasticity with nonlinear isotropic and kinematichardening. J. Mech. Phys. Solids 47, 1589-1607.

Huber, N. Nix, W.D. Gao, H., 2002. Identification of elastic-plastic material parameters from pyramidal indentation of thin films. Proc. Roy. Soc. London A 458, 1593-1620.

Lan, H., Venkatesh, T.A., 2007. Determination of the elastic and plastic properties of materials through instrumented indentation with reduced sensitivity. Acta Mater. 55, 2025-2041.

Larsson, P.L., Giannakopoulos, A.E., SÖderlund, E., Rowcliffe, D.J., Vestergaard, R., 1996. Analysis of Berkovich indentation. Int. J. Solids Struct. 33, 221--248. 
Le, M.-Q., 2008. A computational study on the instrumented sharp indentations with dual indenters. Int. J. Solids Struct. 45, 2818-2835.

Le, M.-Q., 2009. Material characterization by dual sharp indenters. Int. J. Solids Struct. 46, 2988-2998.

Lee, H., Lee J.H., Pharr, G.M., 2005. A numerical approach to spherical indentation techniques for material property evaluation. J. Mech. Phys. Solids 53, 2037-2069.

Lee, Y.-H., Baek, U., Kim, Y.-I., Nahm, S.-H., 2007. On the measurement of pile-up corrected hardness based on the early Hertzian loading analysis. Mater. Lett. 61, 4039-4042.

Liu, L., Ogasawara, N., Chiba, N., Chen, X., 2009. Can indentation technique measure unique elastoplastic properties? J. Mater. Res. 24, 784-800.

Lu, C., Mai, Y.-W., Tam, P.L., Shen, Y.G., 2007. Nanoindentation-induced elastic-plastic transition and size effect in $\alpha-\mathrm{Al}_{2} \mathrm{O}_{3}(0001)$. Philos. Mag. Lett. 87, 409-415.

Luo, J., Lin, J., 2007. A study on the determination of plastic properties of metals by instrumented indentation using two sharp indenters. Int. J. Solids Struct. 44, 5803-5817.

Ma, Z.S., Zhou, Y.C., Long, S.G., Lu, C., 2012. On the intrinsic hardness of a metallic film/substrate system: Indentation size and substrate effects. Int. J. Plasticity 34, $1-11$.

Mata, M., Alcalá, J., 2003. Mechanical property evaluation through sharp indentations in elastoplastic and fully plastic contact regimes. J. Mater. Res. 18, 1705-1709.

Matsuda, K., 2002. Prediction of stress-strain curves of elastic-plastic materials based on the Vickers indentation. Philos. Mag. A 82, 1941-1951.

Matthews, J.R., 1980. Indentation hardness and hot pressing. Acta Metall. 28, 311-318.

McElhaney, K.W., Vlassak, J.J., Nix, W.D., 1998. Determination of indenter tip geometry and indentation contact area for depth-sensing indentation experiments. J. Mater. Res. 13, 1300-1306.

Myers, S., Knapp, J., Follstaedt, D., Dugger, M., 1998. Mechanical properties of 
nickel ion-implanted with titanium and carbon and their relation to microstructure. J. Appl. Phys. 83, 1256-1264.

Norbury, A.L., Samuel, T., 1928. The recovery and sinking-in or piling-up of material in the Brinell test, and the effects of these factors on the correlation of the Brinell with certain other hardness tests. J. Iron Steel Inst. 117, 673-687.

Ogasawara, N., Chiba, N., Chen, X., 2005. Representative strain of indentation analysis. J. Mater. Res. 20, 2225-2234.

Oliver, W.C., Pharr, G.M., 1992. Improved technique for determining hardness and elastic modulus using load and displacement sensing indentation experiments. J. Mater. Res. 7, 1564-1583.

Smith, R., Christopher, D., Kenny, S.D., Richter, A., Wolf, B., 2003. Defect generation and pileup of atoms during nanoindentation of Fe single crystals. Phys. Rev. B 67, 245405.

Swaddiwudhipong, S., Tho, K.K., Liu, Z.S., Zeng, K., 2005. Material characterization based on dual indenters. Int. J. Solids Struct. 42, 69-83.

Tabor, D., 1951. Hardness of Metals. Oxford: Clariendon Press.

Tabor, D., 1996. Indentation hardness: fifty years on a personal view. Philos. Mag. A $74,1207-1212$.

Taljat, B., Pharr, G.M., 2004. Development of pile-up during spherical indentation of elastic-plastic solids. Int. J. Solids Struct. 41, 3891-3904.

Tho, K.K., Swaddiwudhipong, S., Liu, Z.S., Zeng, K., Hua, J., 2004. Uniqueness of reverse analysis from conical indentation tests. J. Mater. Res. 19, 2498-2502.

Tunvisut, K., Busso, E.P., O'Dowd, N.P., Brantner, H.P., 2002. Determination of the mechanical properties of metallic thin films and substrates from indentation tests. Philos. Mag. A 82, 2013-2029.

Tunvisut, K., O'Dowd, N.P., Busso, E.P., 2001. Use of scaling functions to determine mechanical properties of thin coatings from microindentation tests. Int. J. Solids Struct. $38,335-351$.

Wang, Y., Raabe, D., Klüber, C., Roters, F., 2004. Orientation dependence of nanoindentation pile-up patterns and of nanoindentation microtextures in copper 
single crystals. Acta Mater. 52, 2229-2238.

Zeng, K., Chiu, C.h., 2001. An analysis of load-penetration curves from instrumented indentation. Acta Mater. 49, 3539-3551.

Zhao, M., Chen, X., Yan, J., Karlsson, A.M., 2006. Determination of uniaxial residual stress and mechanical properties by instrumented indentation. Acta Mater. 54, $2823-2832$. 


\section{Figure captions}

Fig. 1. Dependence of the pile-up parameter on the strain-hardening exponent $n$ and the ratio $\sigma_{\mathrm{y}} / E$. For comparison, experimental and modeling results are also shown (Norbury and Samuel, 1928; Matthews, 1980; Hill et al., 1989; Biwa and Storakers, 1995).

Fig. 2. Schematic of pile-up and sink-in phenomena after unloading in a sharp indentation.

Fig. 3. Finite element meshing of an axisymmetric indentation: (a) the overall mesh design for a conical indentation and (b) a close-up of the region below the indenter tip.

Fig. 4. Relationships between dimensionless functions and mechanical properties $\left(\sigma_{\mathrm{y}} / E\right.$ and $n$ ) for (a) $F / E h^{2}$, (b) $W_{\mathrm{p}} / W_{\mathrm{t}}$ and (c) $\Delta A / A$. Symbols are numerical results from finite element simulations, and dash lines represent the fitting functions by using Eq. (6). The data of $W_{\mathrm{p}} / W_{\mathrm{t}}$ are from Cheng and Cheng (1999).

Fig. 5. Mechanical behaviors of three highly plastic materials: (a) stress-strain curves (symbols represent results from the reverse analysis), (b) $P-h$ curves (where $W_{\mathrm{e}}$ is the elastic work and $W_{\mathrm{p}}$ is the plastic work), and (c) indentation profiles after unloading.

Fig. 6. Mechanical behaviors of three highly elastic materials: (a) stress-strain curves (symbols represent results from the reverse analysis) and (b) $P-h$ curves (where $W_{\mathrm{e}}$ is the elastic work and $W_{\mathrm{p}}$ is the plastic work). 
Fig. 7. Error analysis on the elastic modulus, yield strength and hardening exponent.

Fig. 8. A pair of mystical materials with $E_{1}=100.00 \mathrm{GPa}, \sigma_{\mathrm{y} 1}=793.15 \mathrm{MPa}, n_{1}=$ 0.02 (solid line) and $E_{2}=103.75 \mathrm{GPa}, \sigma_{\mathrm{y} 2}=600.68 \mathrm{MPa}, n_{2}=0.15046(\mathrm{dash}$ line). (a) The $P-h$ curves of mystical materials and the pile-up curves (see inset at top-left corner) and (b) the $\sigma-\varepsilon$ curves of mystical materials (symbols represent results from the reverse analysis).

Fig. 9. A pair of extreme mystical materials with $E_{1}=100.00 \mathrm{GPa}, \sigma_{\mathrm{y} 1}=872.47$ $\mathrm{MPa}, n_{1}=0.0$ (solid line) and $E_{2}=103.75 \mathrm{GPa}, \sigma_{\mathrm{y} 2}=715.61 \mathrm{MPa}, n_{2}=$ 0.10663 (dash line). (a) The $P-h$ curves of mystical materials and the pile-up curves (see inset at top-left corner) and (b) the $\sigma-\varepsilon$ curves of mystical materials (symbols represent results from the reverse analysis).

Fig. 10. Error analysis on the elastic modulus, yield strength and hardening exponent for two pairs of mystical materials.

Fig. 11. Schematic diagram of a triangular pyramid indenter with three symmetry planes and the symmetry model for three-dimensional finite element analysis.

Fig. 12. Comparison of the $P-h$ curves between finite element simulations and experimental data from Dao et al. (2001) for Al6061.

Fig. 13. Relationships between dimensionless functions and mechanical properties $\left(\sigma_{\mathrm{y}} / E\right.$ and $n$ ) for (a) $F / E h^{2}$, (b) $W_{\mathrm{p}} / W_{\mathrm{t}}$ and (c) $\Delta A / A$. Symbols are numerical results from finite element simulations of a three-dimensional Berkovich indenter, and dash lines represent the fitting functions by using Eq. (6). 
Fig. 14. Mechanical behaviors of a single crystal aluminum material: (a) the $P-h$ curve and indentation profile after unloading and (b) stress-strain curves (symbols represent results from the reverse analysis). 


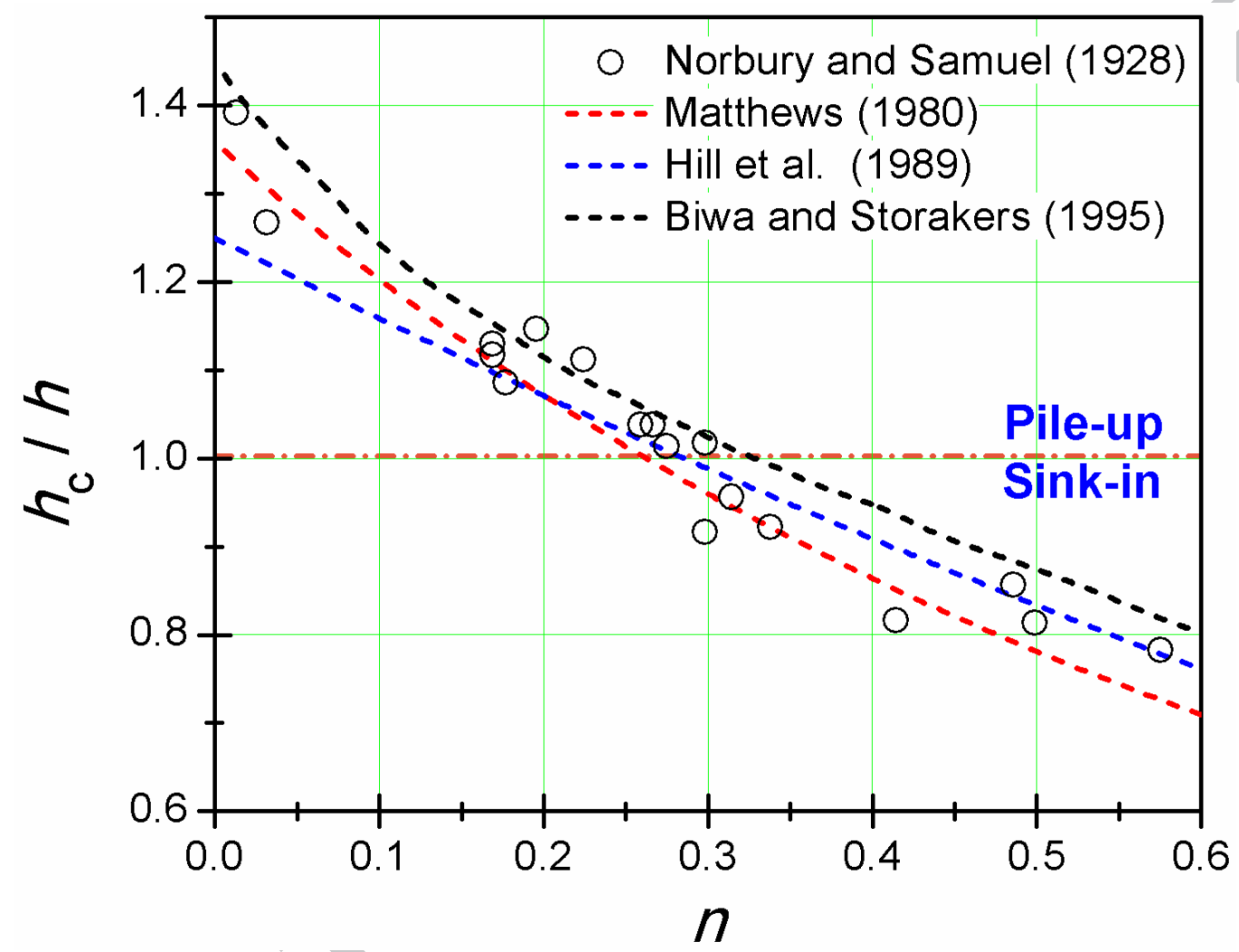

Fig. 1 


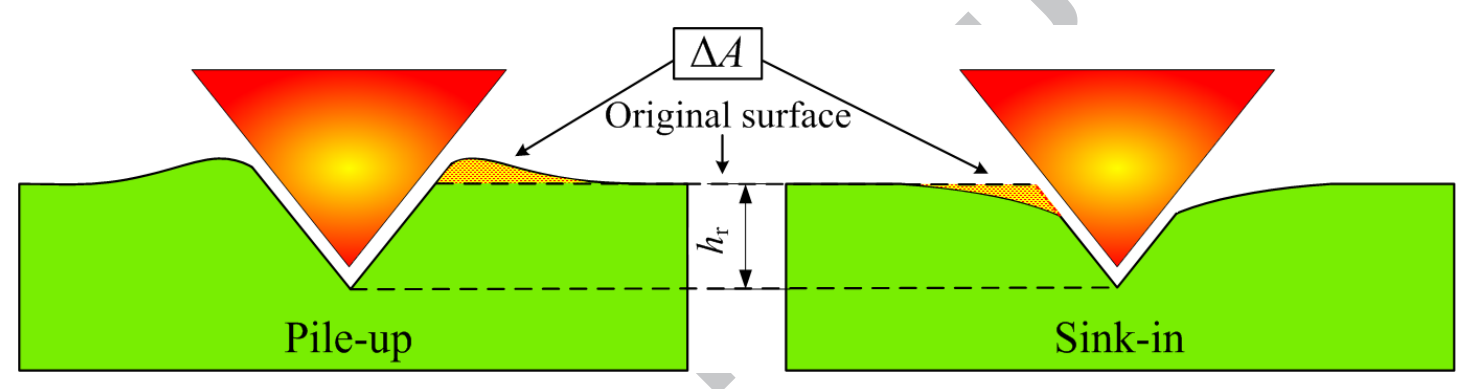

Fig. 2 
(a) Region below the indenter tip

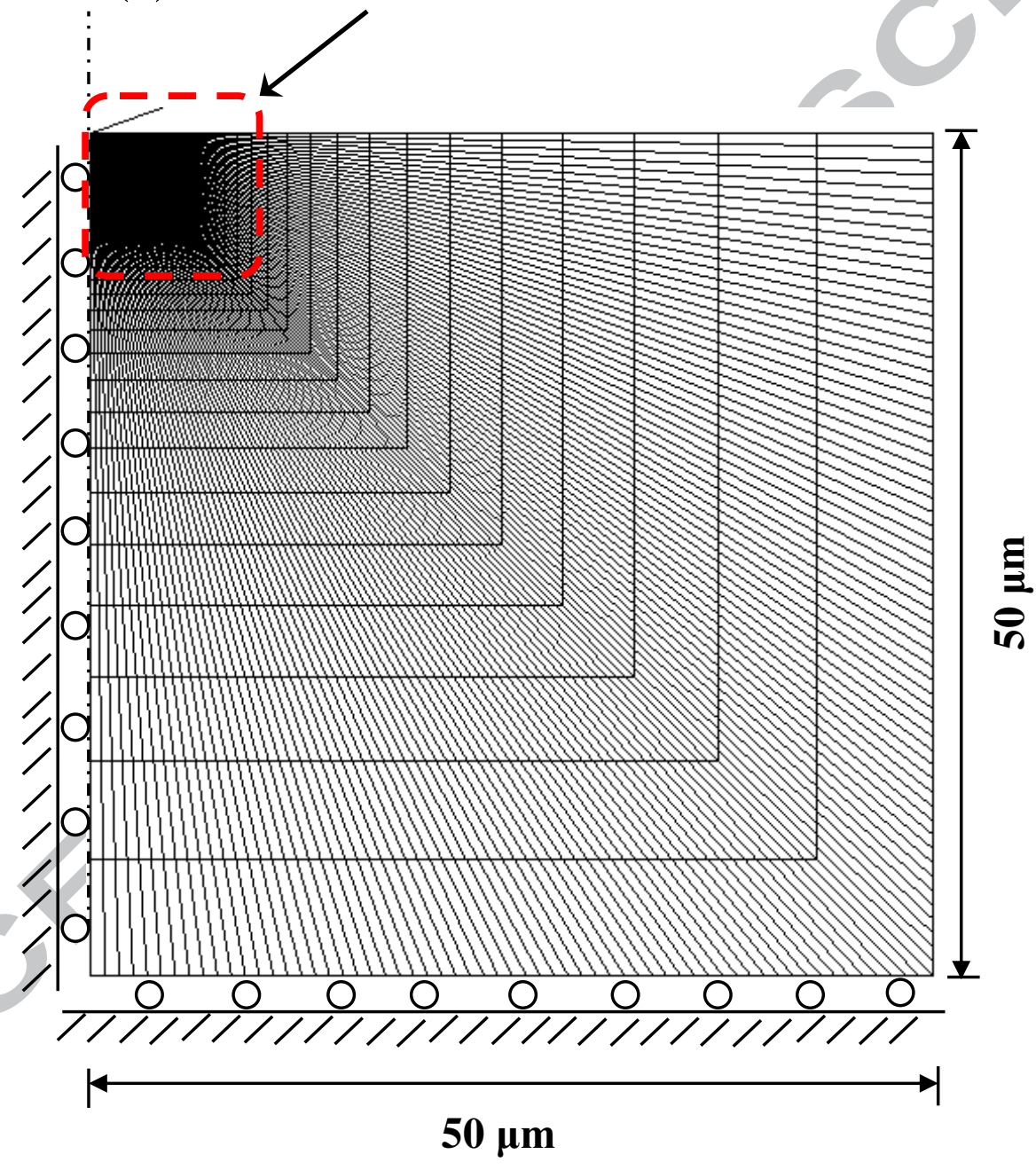


(b)

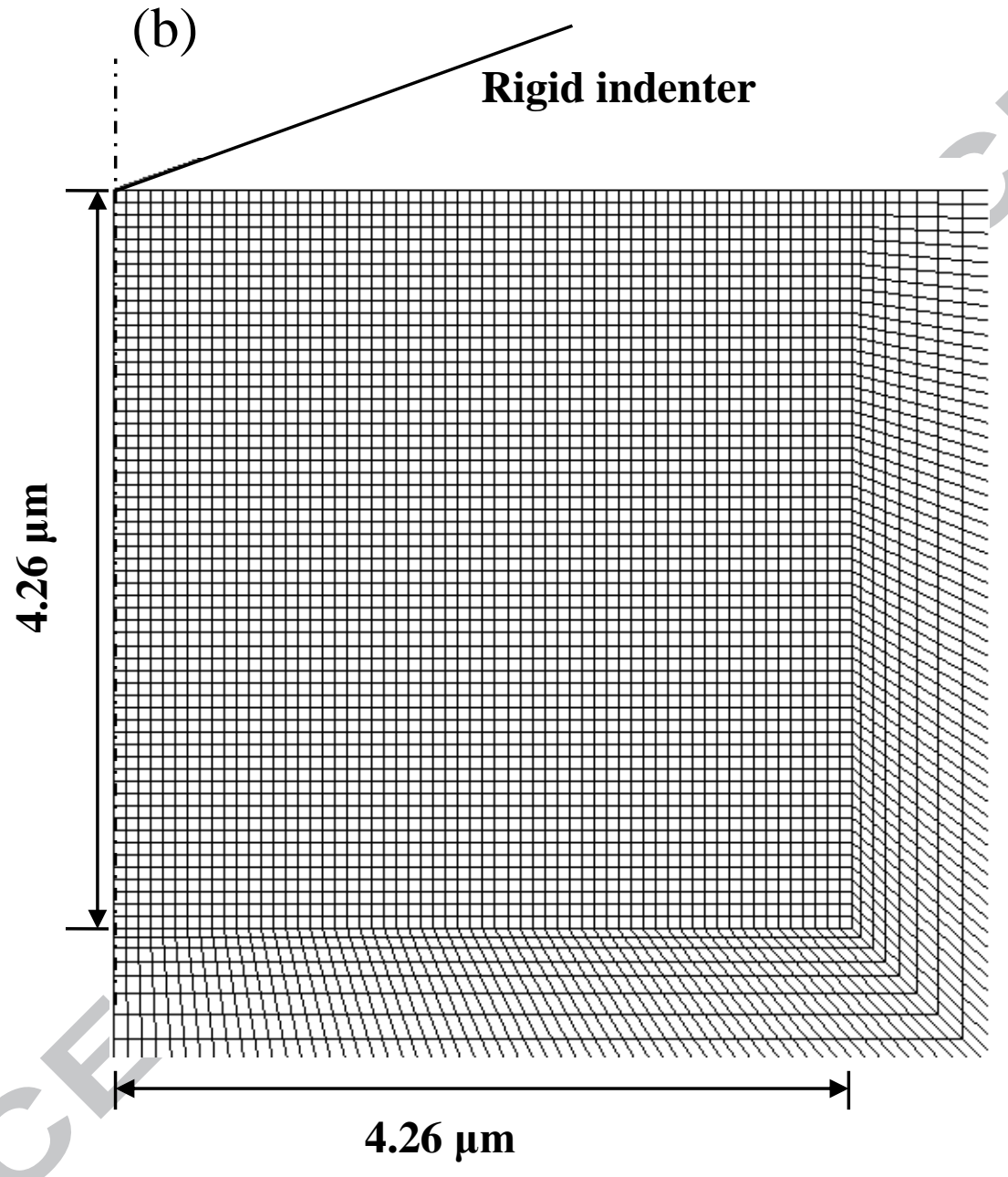

Fig. 3 


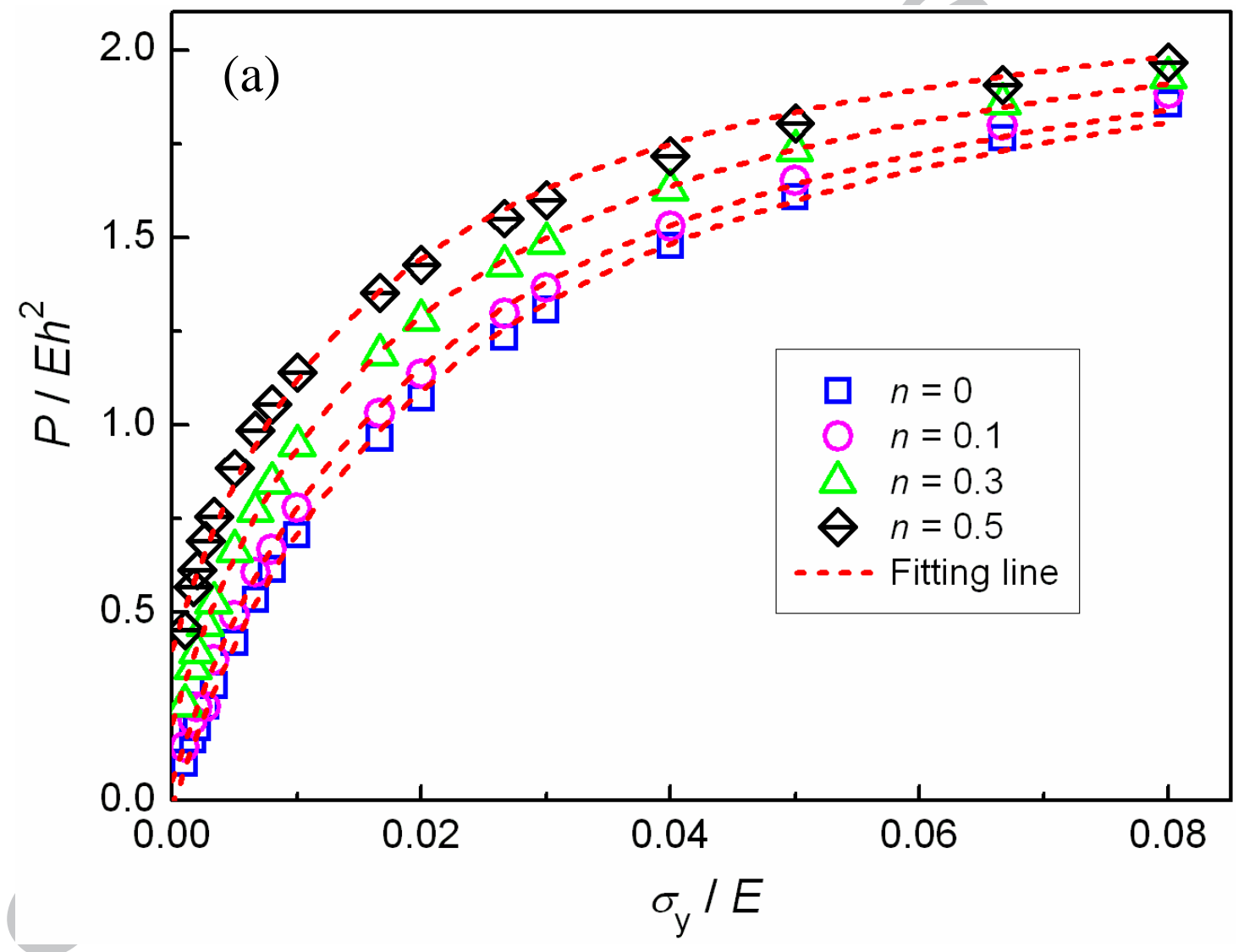




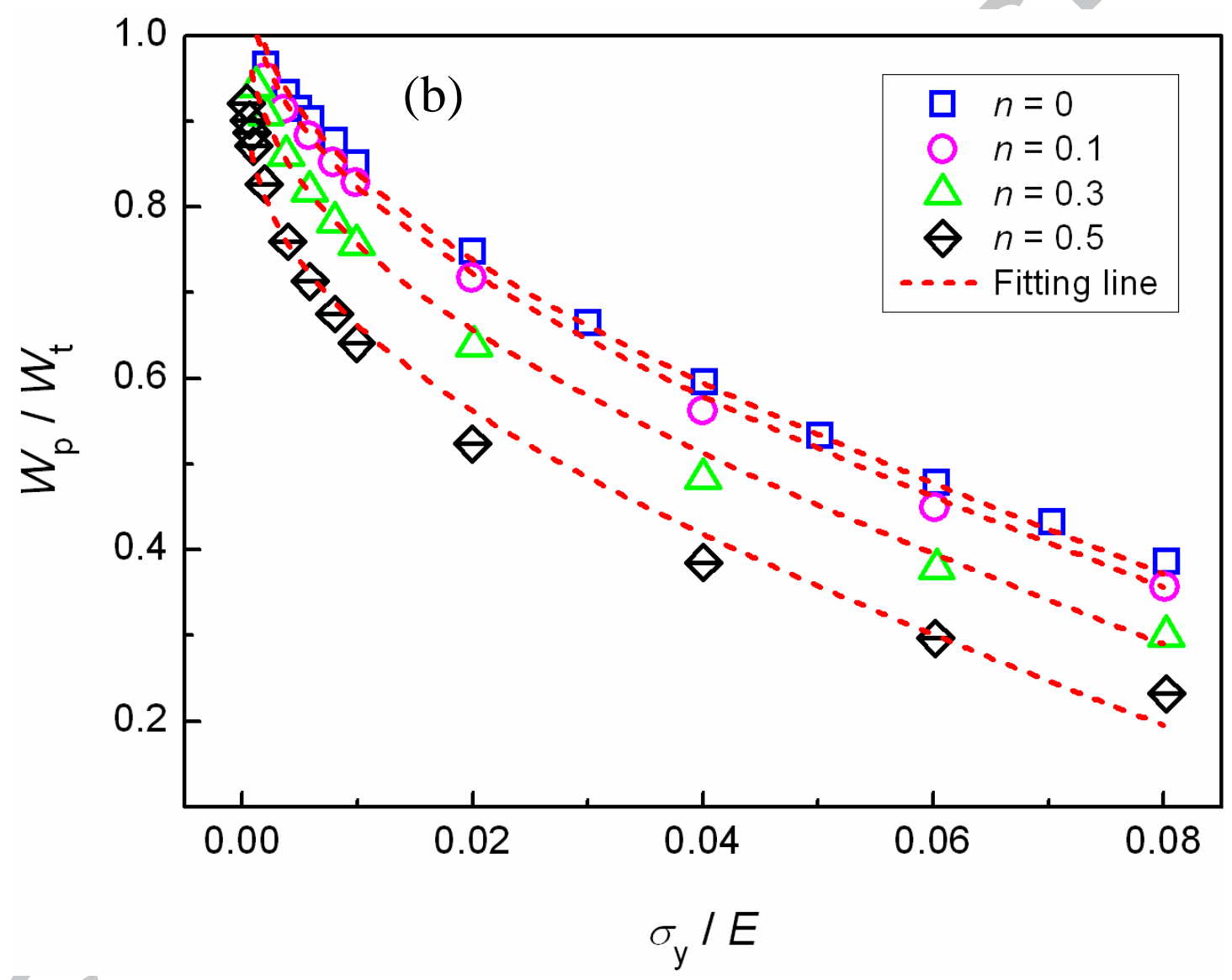




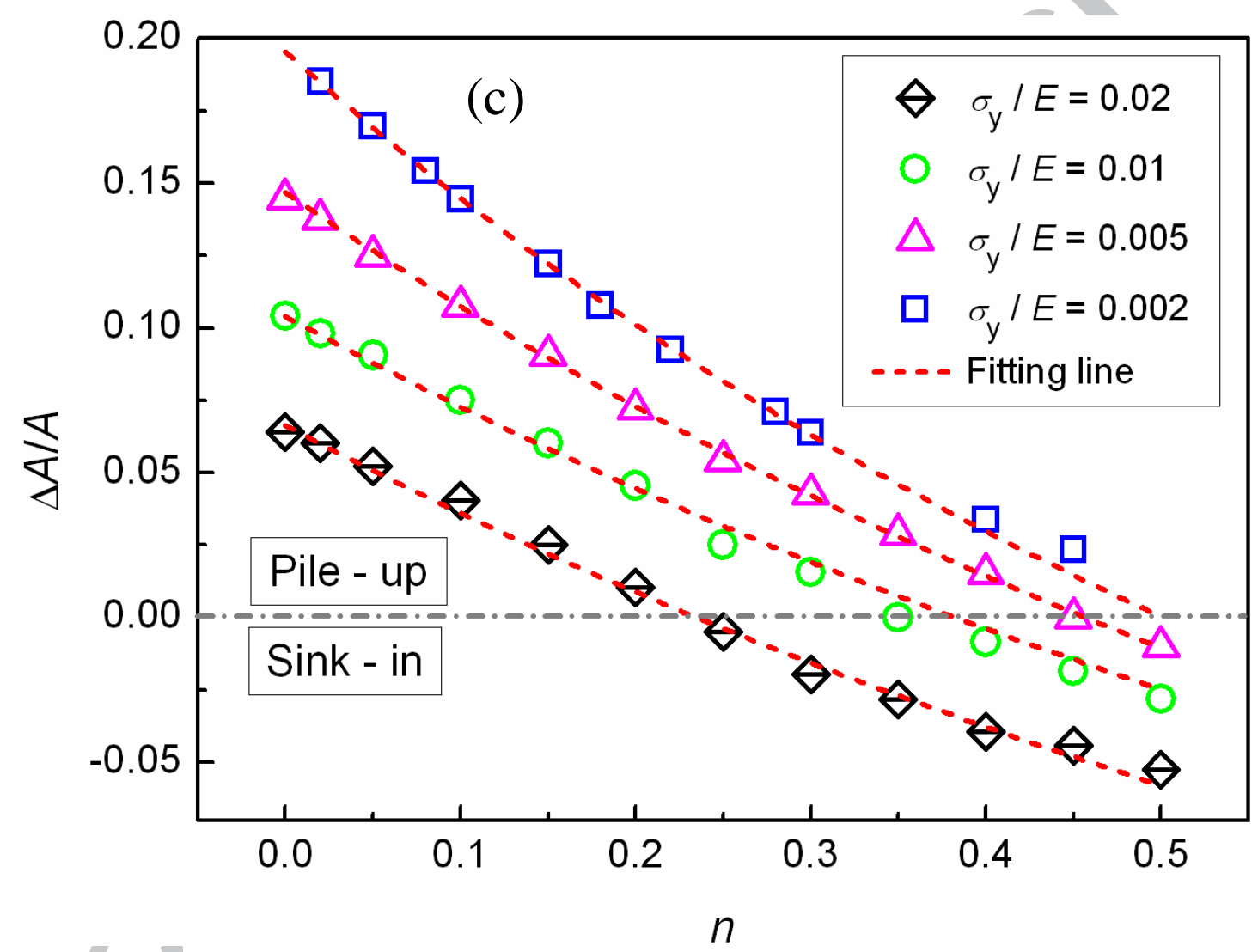

Fig. 4 


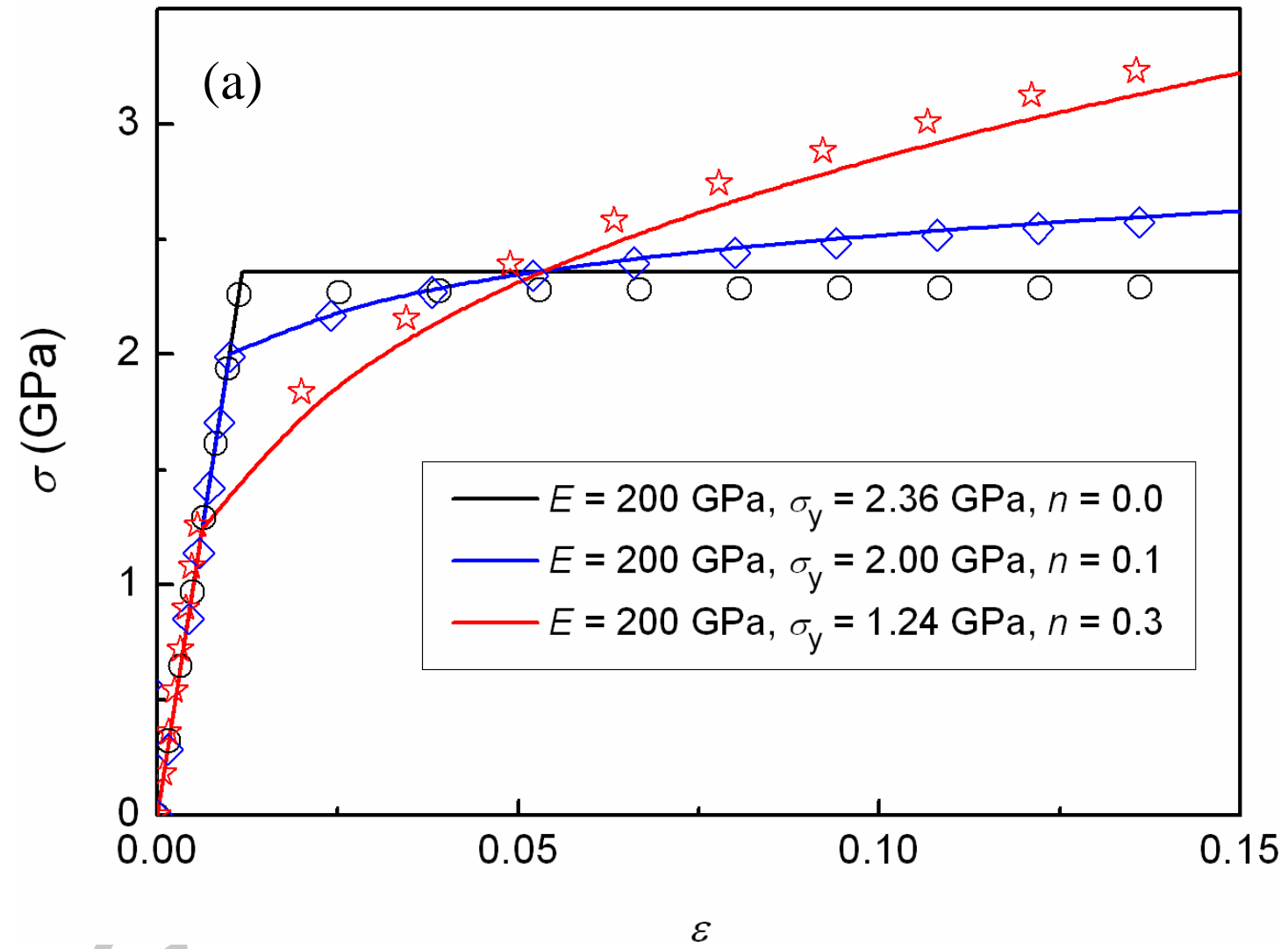




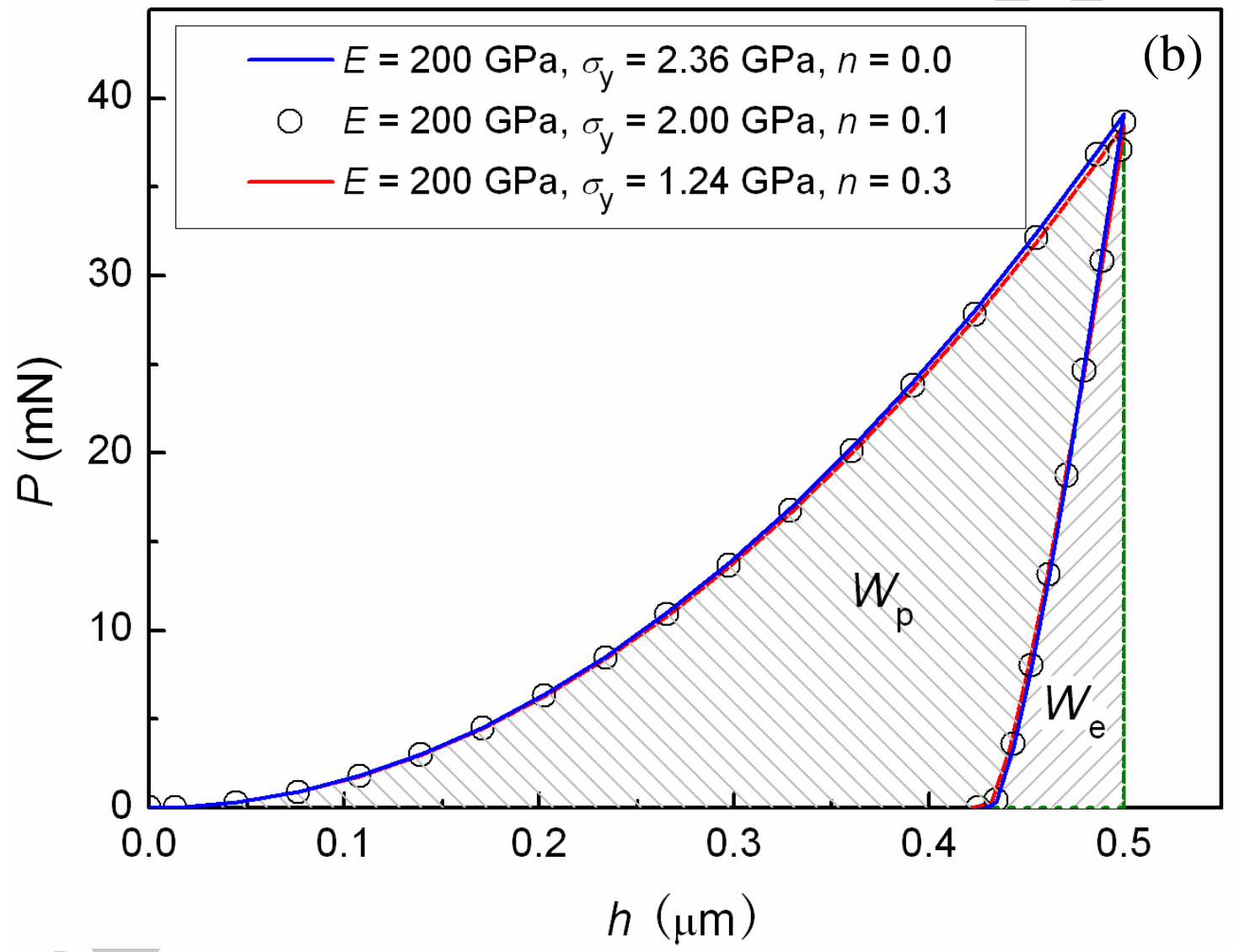




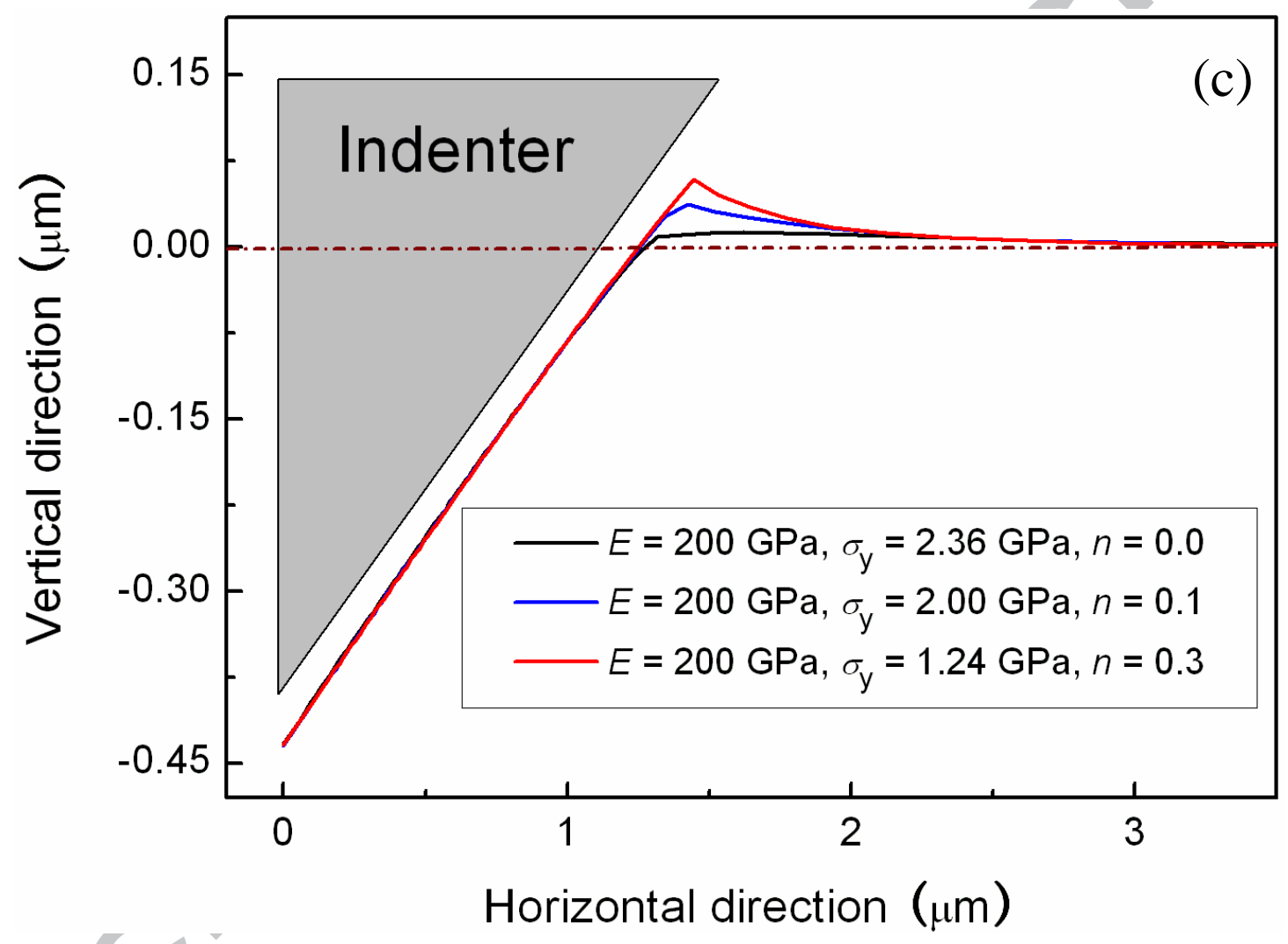

Fig. 5 


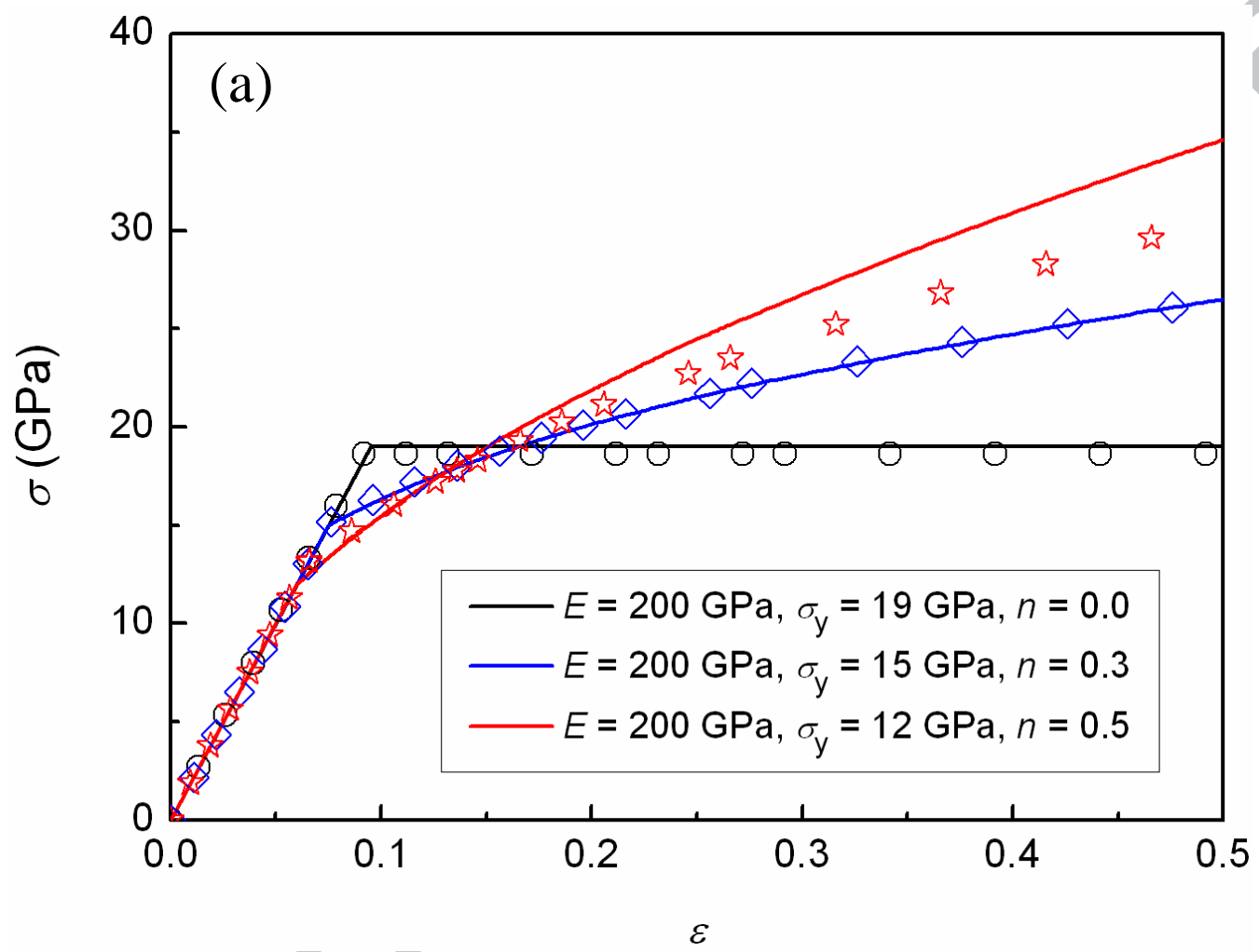




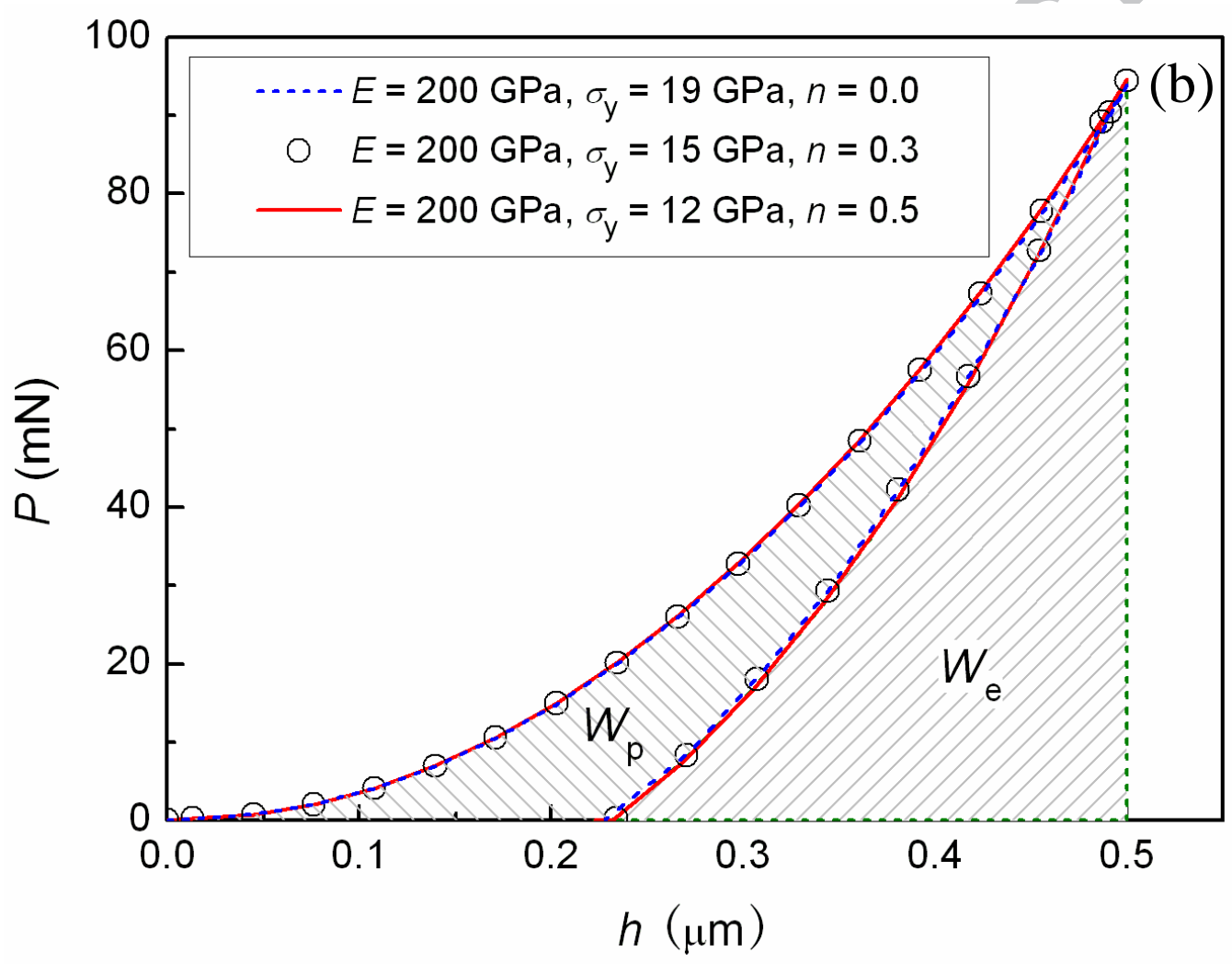

Fig. 6 


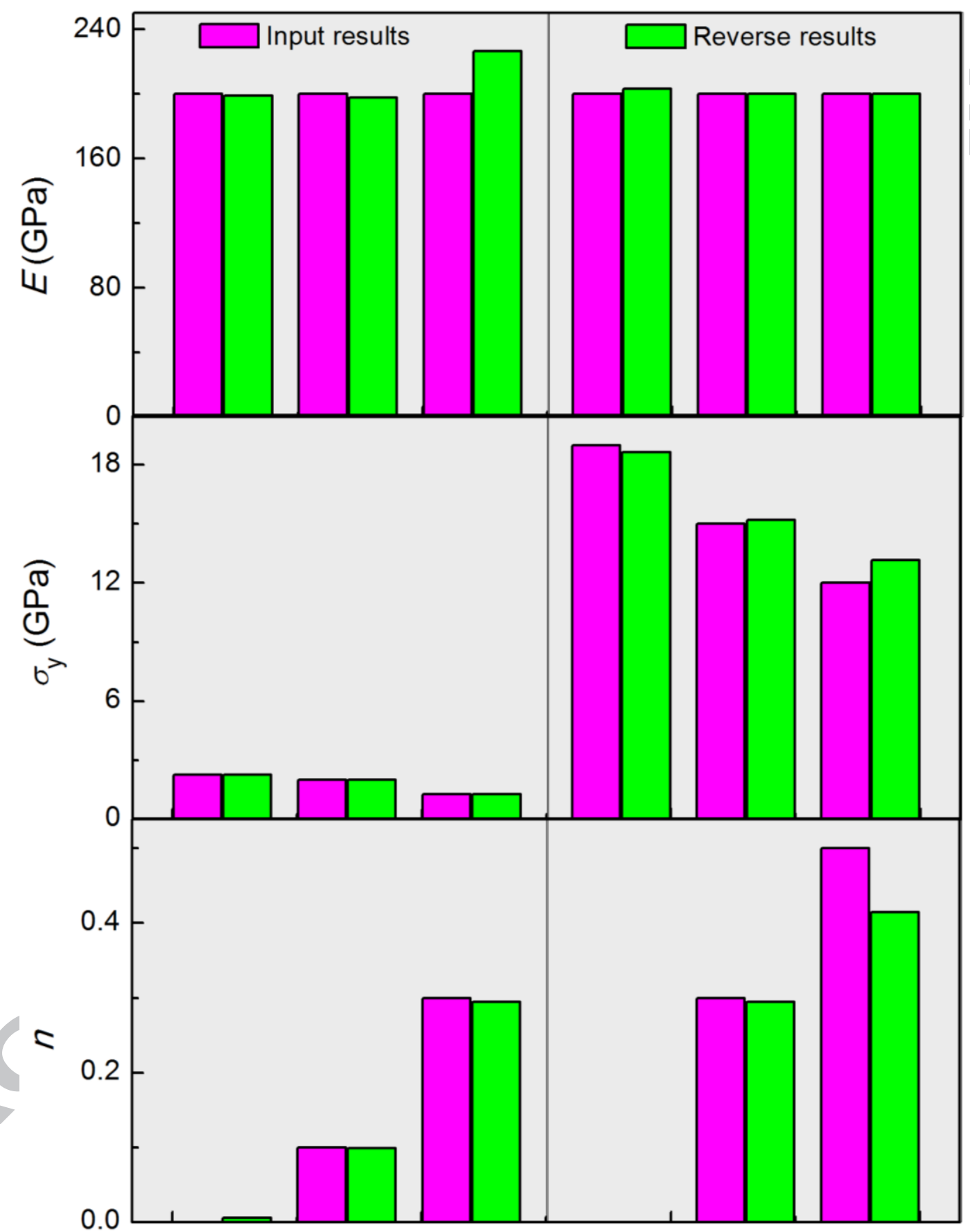

Highly plastic solids

Highly elastic solids

Fig. 7 


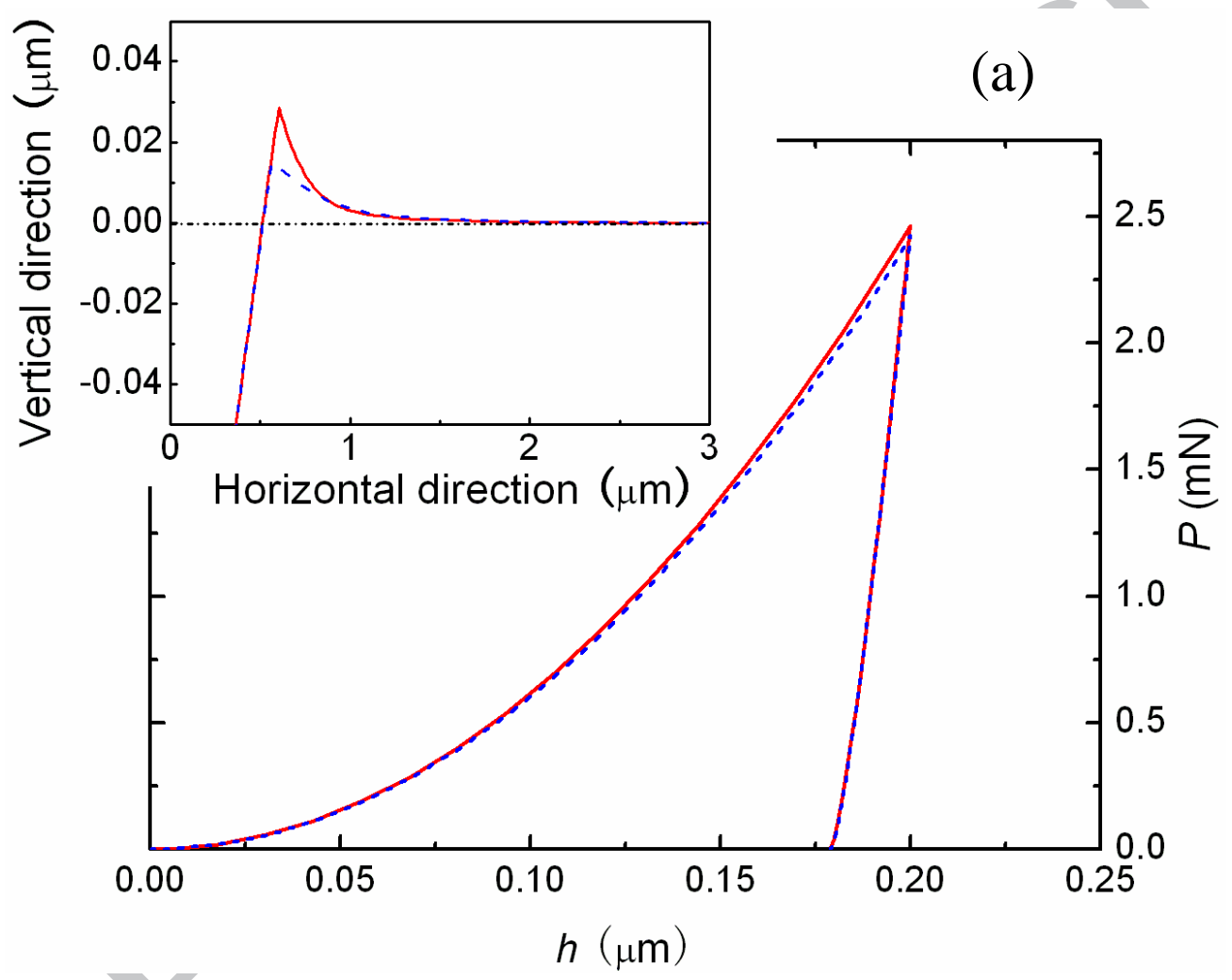




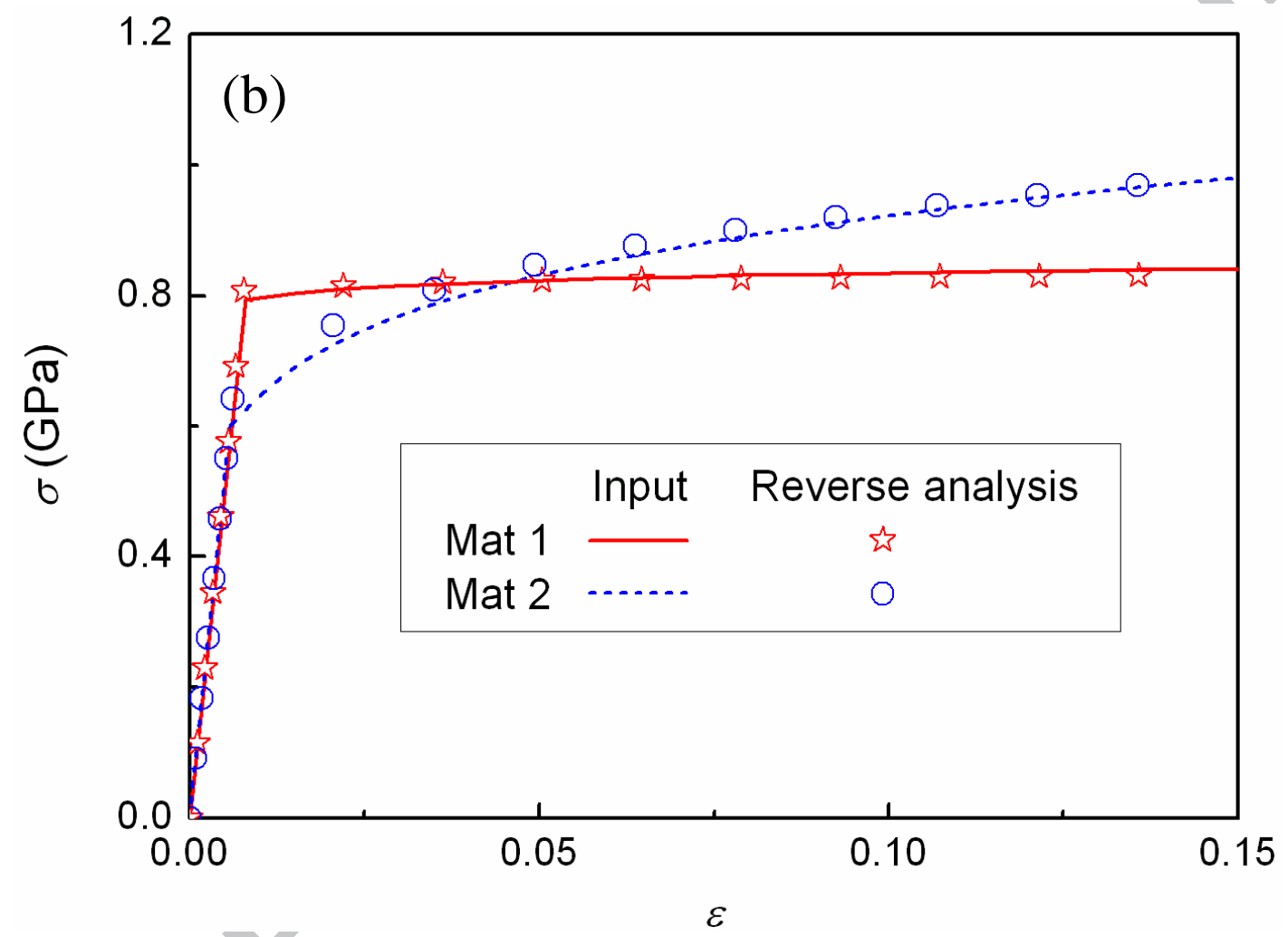

Fig. 8 


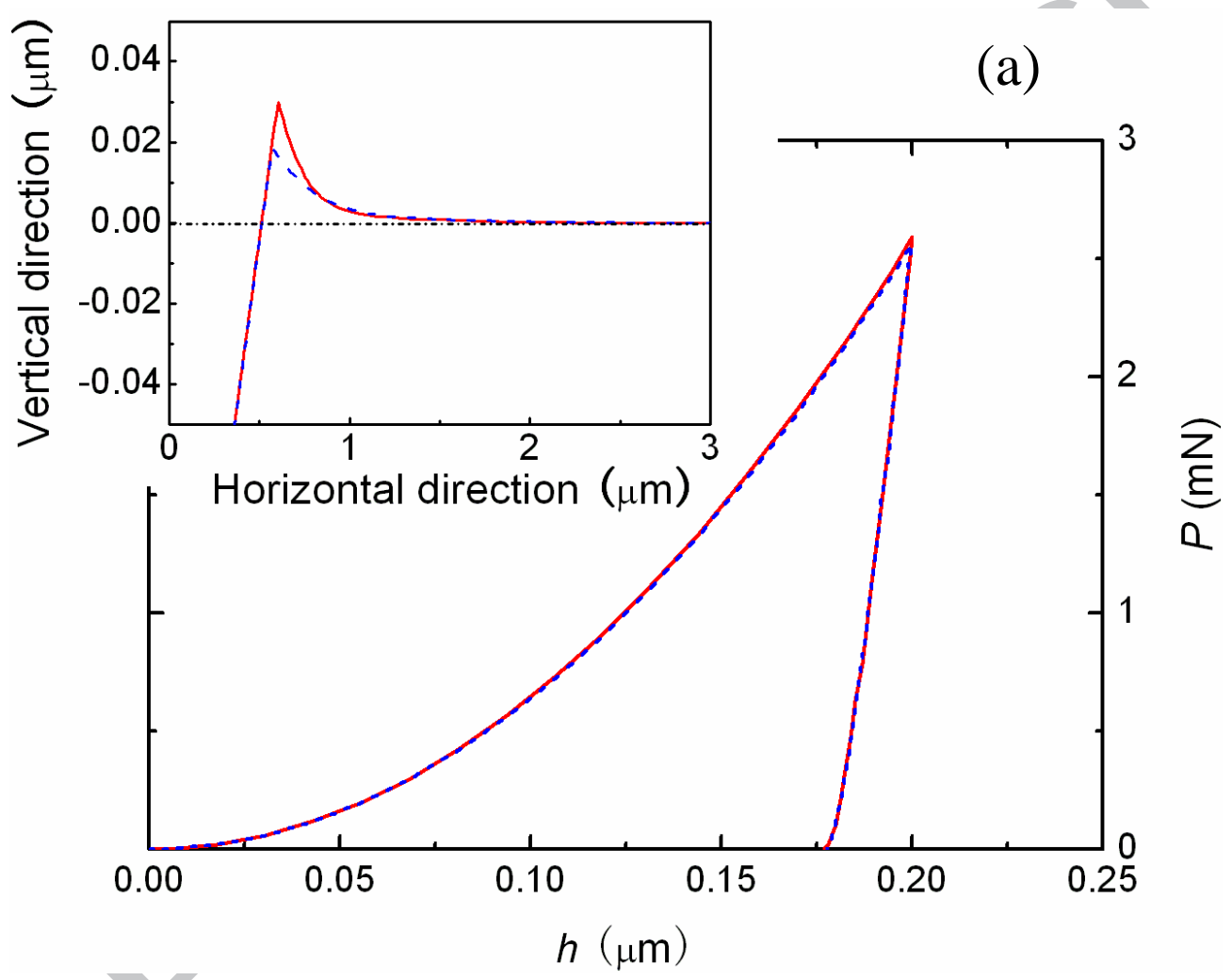




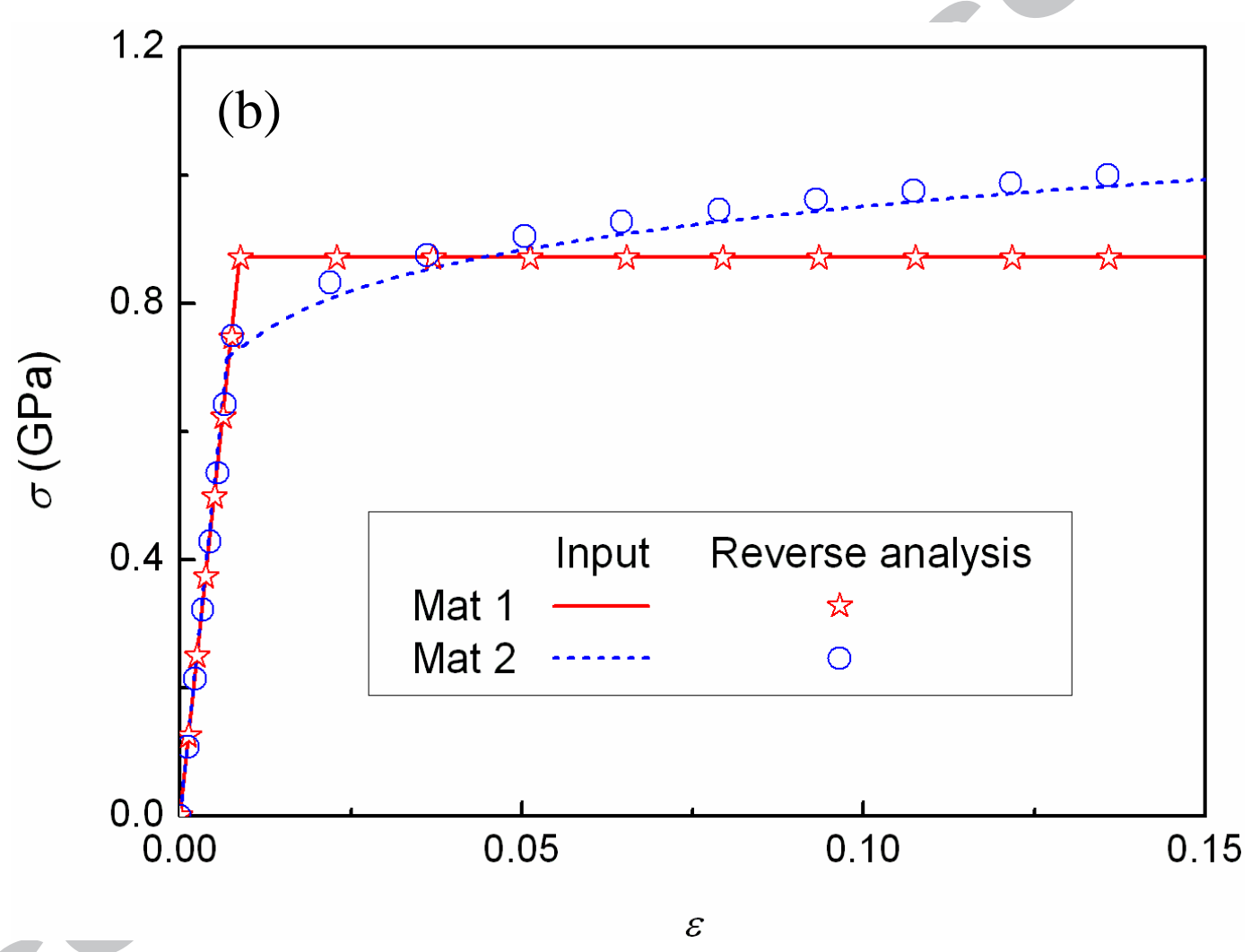

Fig. 9 


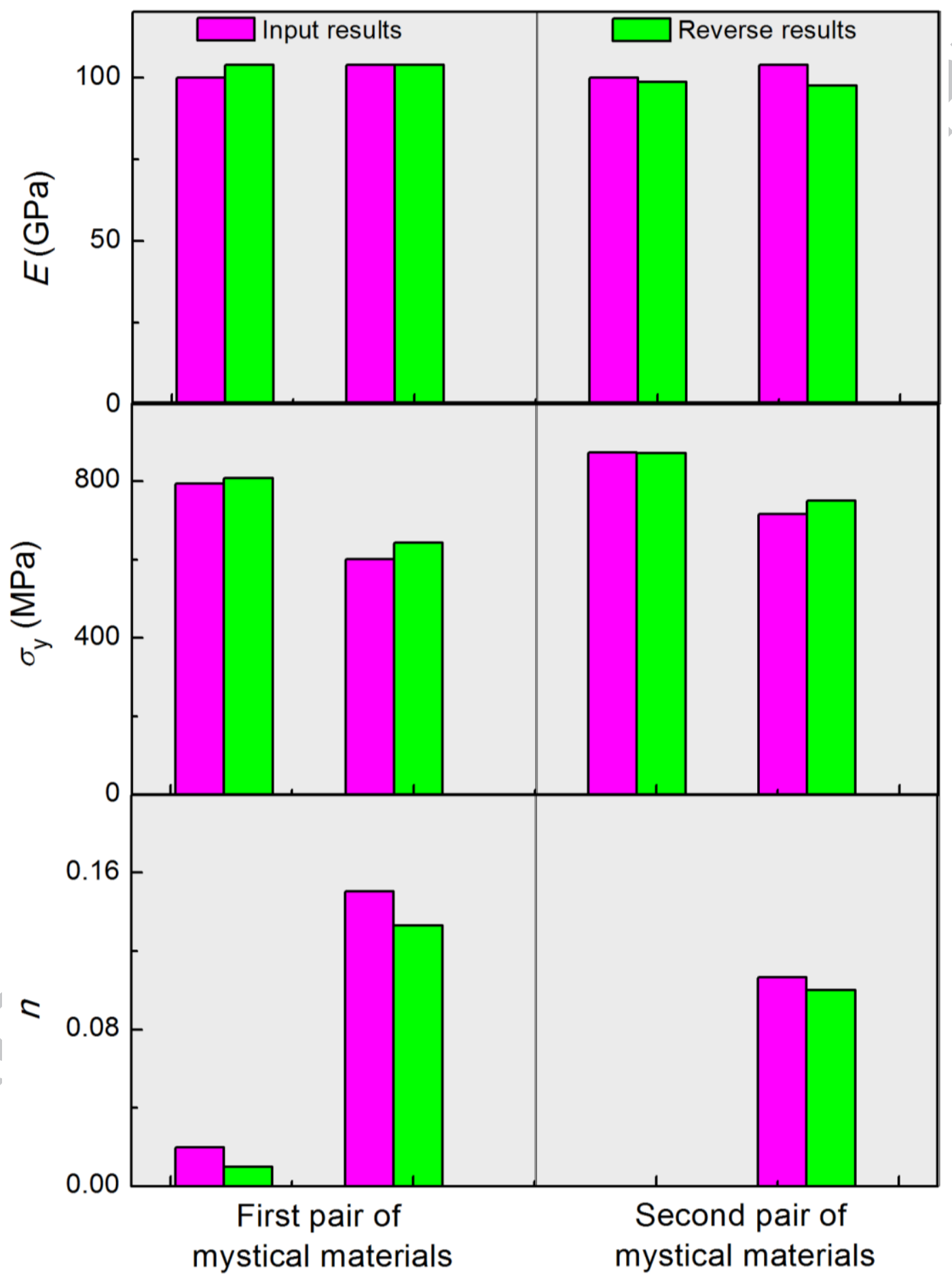

Fig. 10 


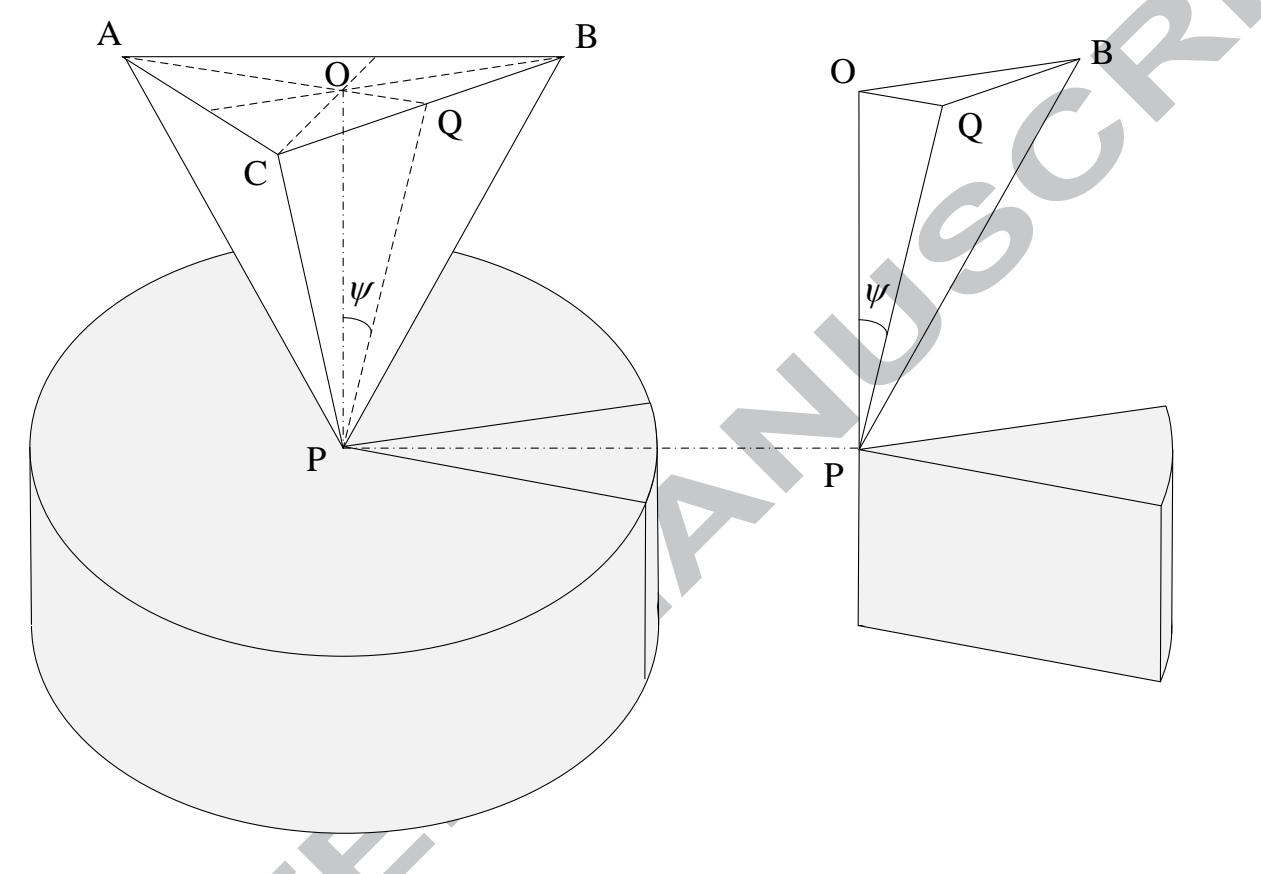

Fig. 11 


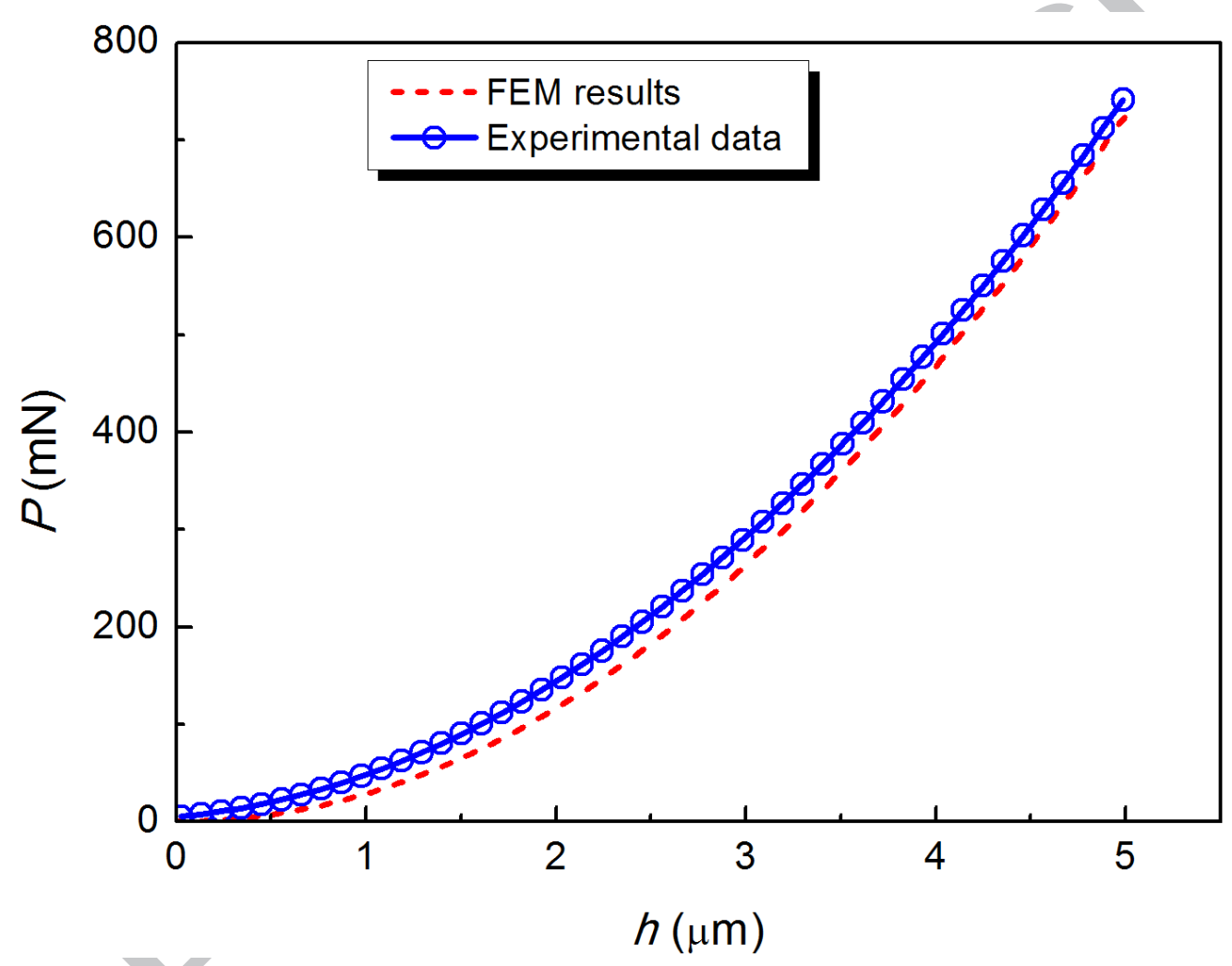

Fig. 12 


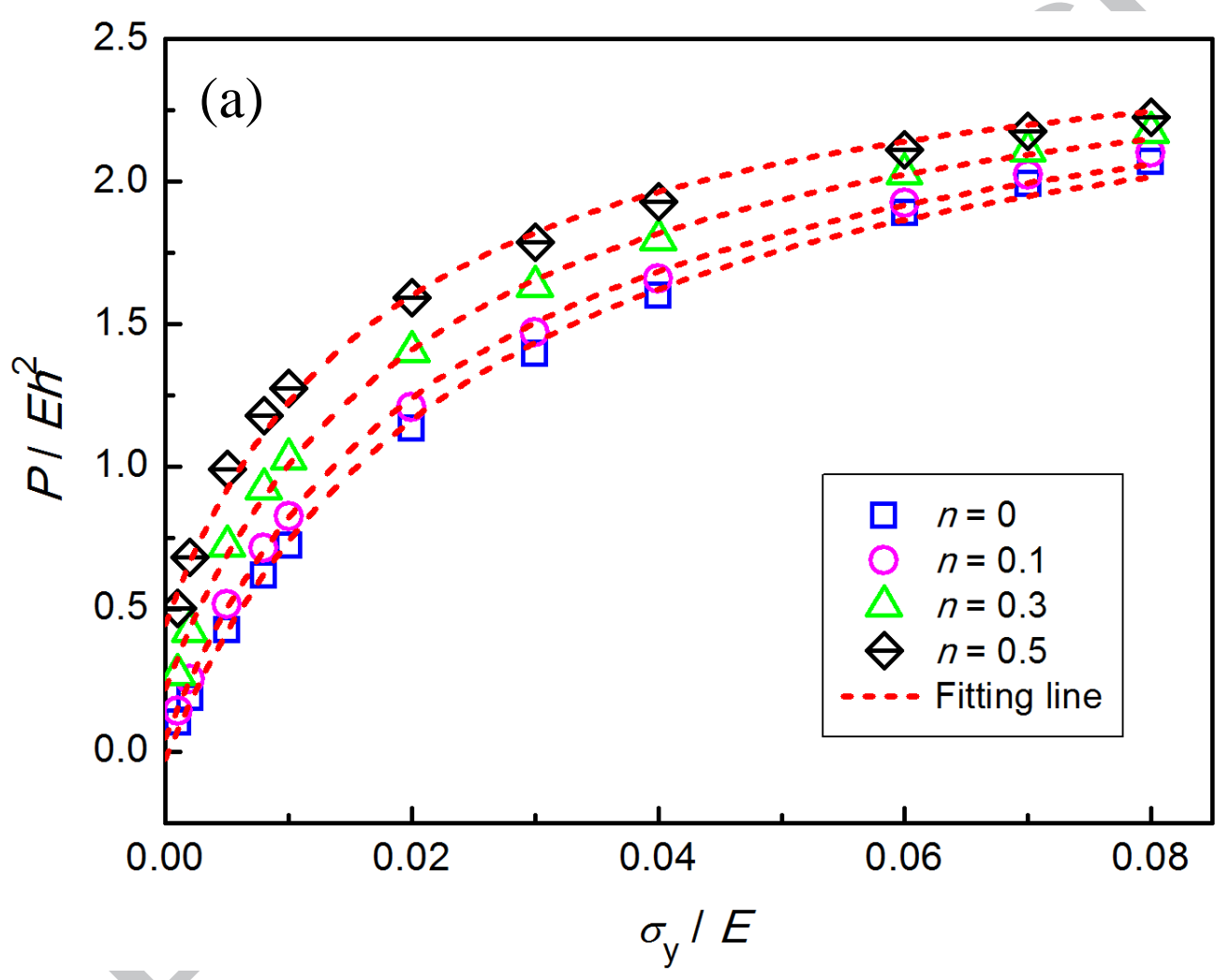




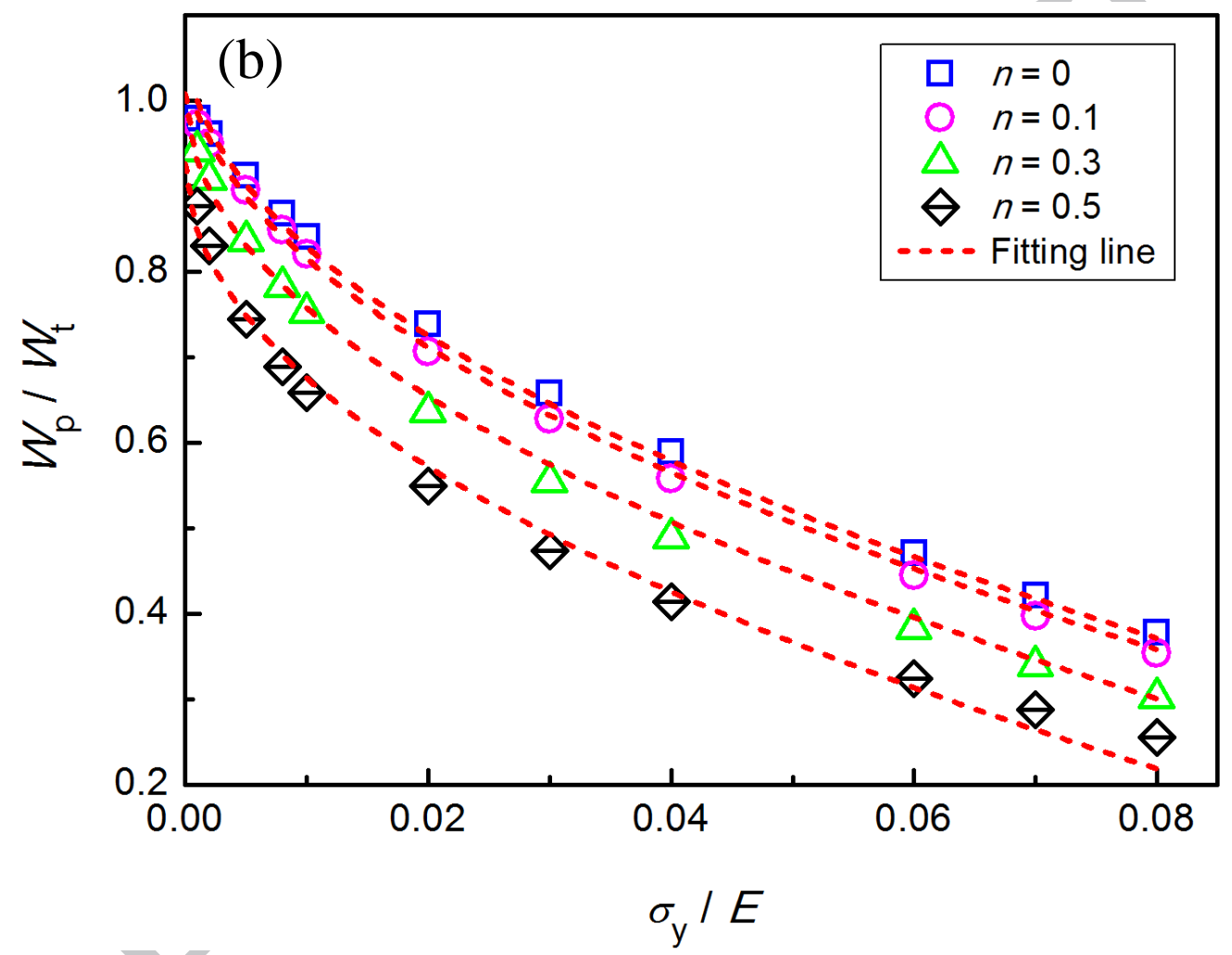




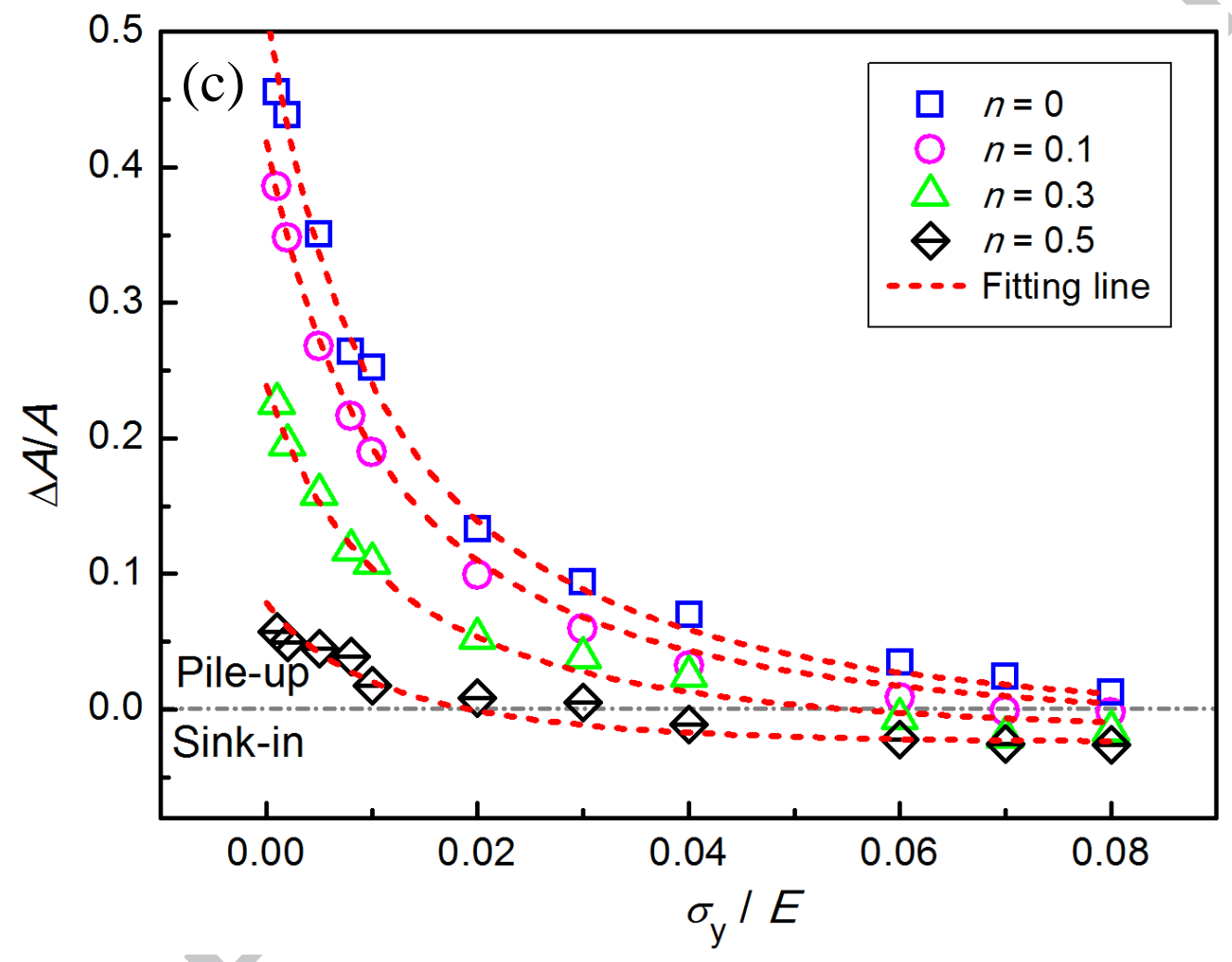

Fig. 13 


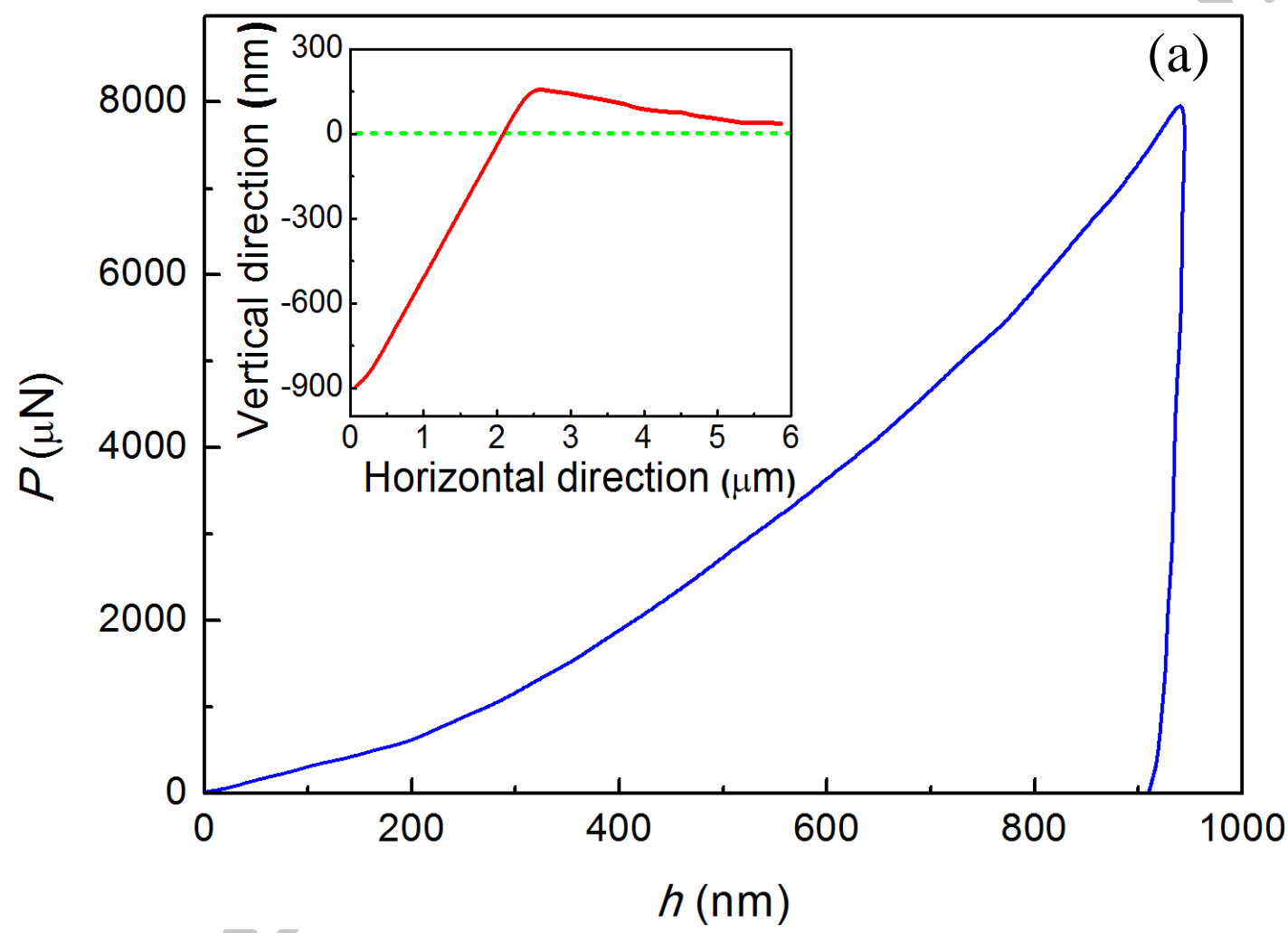




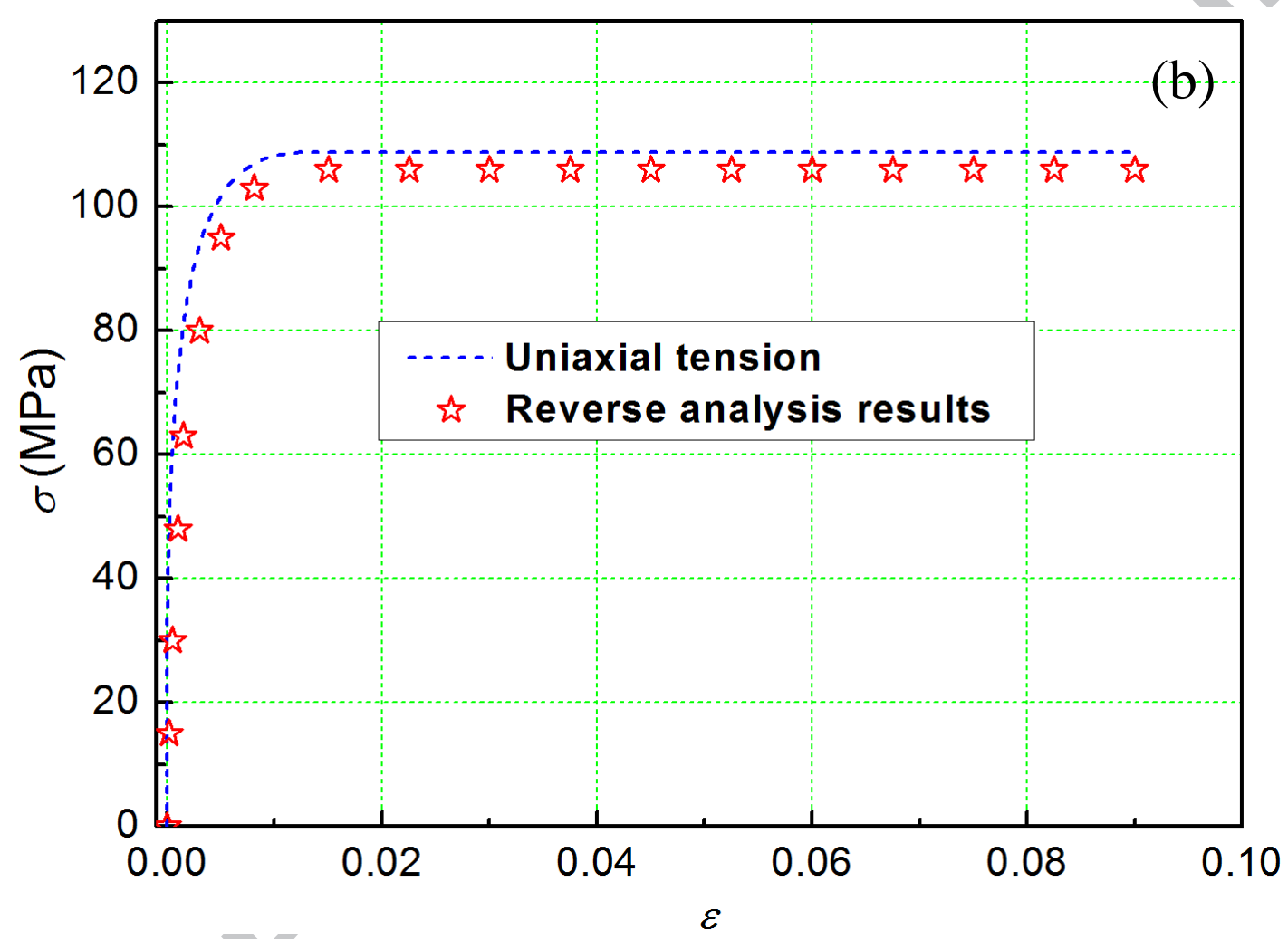

Fig. 14 
Table 1. Results obtained from the reverse analysis on the materials in Cheng and Cheng (1999).

\begin{tabular}{|c|c|c|c|c|c|c|c|c|c|c|c|c|}
\hline \multirow{2}{*}{ Materials } & \multicolumn{3}{|c|}{ Input data } & \multicolumn{6}{|c|}{ Parameters from indentation } & \multicolumn{3}{|c|}{ Reverse results } \\
\hline & $E / \mathrm{GPa}$ & $\sigma_{\mathrm{y}} / \mathrm{GPa}$ & $n$ & $\Delta A / \mu \mathrm{m}^{2}$ & $A / \mu \mathrm{m}^{2}$ & $W_{\mathrm{p}} / \mathrm{J}^{-9}$ & $W_{\mathrm{t}} / \mathrm{J}^{-9}$ & $h_{\mathrm{m}} / \mu \mathrm{m}$ & $P / \mathrm{mN}$ & $E / \mathrm{GPa}$ & $\sigma_{\mathrm{y}} / \mathrm{GPa}$ & $n$ \\
\hline Highly & 200 & 2.36 & 0.0 & 0.0330 & 0.349 & 5.319 & 6.463 & 0.5 & 38.66 & 198.73 & 2.26 & 0.006 \\
\hline plastic & 200 & 2.00 & 0.1 & 0.0253 & 0.349 & 5.319 & 6.463 & 0.5 & 38.66 & 197.75 & 1.99 & 0.099 \\
\hline solids & 200 & 1.24 & 0.3 & 0.0140 & 0.349 & 5.319 & 6.463 & 0.5 & 38.66 & 226.48 & 1.26 & 0.295 \\
\hline Highly & 200 & 19.00 & 0.0 & 0.0058 & 0.349 & 4.875 & 15.59 & 0.5 & 94.42 & 203.27 & 18.65 & 0.000 \\
\hline elastic & 200 & 15.00 & 0.3 & 0.0110 & 0.349 & 4.875 & 15.59 & 0.5 & 94.42 & 199.87 & 15.19 & 0.295 \\
\hline
\end{tabular}

Table 2. Results obtained from the reverse analysis on the mystical materials in Chen et al. (2007)

\begin{tabular}{|c|c|c|c|c|c|c|c|c|c|c|c|c|}
\hline \multirow{2}{*}{ Materials } & \multicolumn{3}{|c|}{ Input data } & \multicolumn{6}{|c|}{ Parameters from indentation } & \multicolumn{3}{|c|}{ Reverse results } \\
\hline & $E / \mathrm{GPa}$ & $\sigma_{\mathrm{y}} / \mathrm{GPa}$ & $n$ & $\Delta A / \mu \mathrm{m}^{2}$ & $A / \mu \mathrm{m}^{2}$ & $W_{\mathrm{p}} / \mathrm{J}^{-9}$ & $W_{\mathrm{t}} / \mathrm{J}^{-9}$ & $h_{\mathrm{m}} / \mu \mathrm{m}$ & $P / \mathrm{mN}$ & $E / \mathrm{GPa}$ & $\sigma_{\mathrm{y}} / \mathrm{GPa}$ & $n$ \\
\hline \multirow{2}{*}{ First pair } & 100.00 & 0.79315 & 0.02000 & 0.00684 & 0.0559 & 0.14169 & 0.16443 & 0.2 & 2.466 & 103.76 & 0.807 & 0.010 \\
\hline & 103.75 & 0.60068 & 0.15046 & 0.00480 & 0.0559 & 0.13868 & 0.16109 & 0.2 & 2.426 & 103.92 & 0.642 & 0.133 \\
\hline Second pair & 103.75 & 0.71561 & 0.10663 & 0.00481 & 0.0559 & 0.14587 & 0.17076 & 0.2 & 2.560 & 97.56 & 0.750 & 0.100 \\
\hline
\end{tabular}


- A new method is proposed for solving the uniqueness of reverse analysis in indentation.

- The method is based on an additional dimensionless function.

- The so-called mystical materials can be successfully distinguished. 